\title{
Benzilic acid based new 2-aryl-1,3-thiazolidin-4-one derivatives: Synthesis and anticancer activity
}

\author{
Özlen GÜZEL-AKDEMİR ${ }^{1}$ (D), Kübra DEMİR-YAZICI ${ }^{*}$ * \\ 1 Department of Pharmaceutical Chemistry, Faculty of Pharmacy, Istanbul University, Fatih 34116 Istanbul, Turkey. \\ * Corresponding Author. E-mail: kubra.demir@istanbul.edu.tr (K.D.-Y.); Tel. +90-212-440 00 00/13462.
}

Received: 09 December 2020 / Revised: 23 March 2021 / Accepted: 26 March 2021

ABSTRACT: Some new derivatives of 2-aryl-1,3-thiazolidin-4-one derivatives were produced (3a-p and 4a-p) in the search of potentially active new molecules with antitumor features. Compounds were obtained by cyclocondensation of 2-hydroxy-2,2-diphenyl-N-[(substituted phenyl)methylene]acetohydrazides (2) and mercaptoacetic acid or 2mercaptopropionic acid. Identification and characterization of 32 new 2-aryl substituted thiazolidin-4-ones were performed with spectral and elemental analyzes. Compound $\mathbf{3 c}, \mathbf{3 g}, \mathbf{3 j}, \mathbf{4 g}$, $\mathbf{4 n}$, and $\mathbf{4} \mathbf{p}$ were chosen as prototypes and assayed for their anticancer activity against diverse several cancer cell lines with in vitro primary anticancer test in the National Cancer Institute. Compound $\mathbf{4 g}$ exhibited significant anticancer activity with the inhibition value $84.19 \%$ against a leukemia cell line MOLT-4 while compound $4 \mathbf{p}$ had a remarkable inhibition ratio $(72.11 \%)$ against the growth of a CNS (central nervous system) cancer cell line SF-295 in the primary screen. These preliminary and important results indicated that the compounds carried 2-aryl-1,3-thiazolidin-4-one scaffold can be evaluated as potentially promising anticancer agents.

KEYWORDS: 1,3-Thiazolidin-4-one; benzilic acid; mercaptoacetic acid; 2-mercaptopropionic acid; anticancer agents.

\section{INTRODUCTION}

One of the most common death cause is cancer globally and remains a life-threatening health problem all over the world. According to the GLOBOCAN (Global Cancer Observatory) data, an estimated 18.1 million cases and 9.6 million deaths in 2018 caused by different types of cancers are recorded [1]. In 2020, the number of new cases is expected to increase to 15 million [2]. It is known that the most common cancer cases and causes of cancer deaths are closely related to the degree of socio-economic levels of countries, distribution of main risk factors for cancers, aging, and growth of the population and lifestyles [3]. Cancer treatment can be collected under three main methods: Resection of the primary tumor, chemotherapy, or radiotherapy, which could have varying success or cause a different range of short and long-term adverse health effects [4]. Today, cancer researches focus on finding new and more effective treatment techniques like "targeted" therapy, which targets particularly single or a class of molecular targets in cancer cells [5]. Therefore it is a remarkable application area to develop cancer cell-targeted and selective new anticancer agents in medicinal chemistry.

Heterocyclic structures which have sulfur and nitrogen are a known class of molecules which provide numerous possibility for synthesis of new physiologically active compounds [6,7]. Especially 4-thiazolidinone scaffold takes great attention due to its several biological properties like antimicrobic, antiparasitic, antioxidant, anticonvulsant, anti-HIV, anti-inflammatory, anti-tubercular, antifungal, and particularly anticancer [8-11]. In recent decades, investigation of 4-thiazolidinone derivatives for its antitumor activity on colon, breast, renal, lung, prostate, ovarian, melanoma, leukemia, and CNS (central nervous system) cancers cell lines have an increasing trend for anticancer drug discovery $[12,13]$. Due to its wide range of biological potentials, in our previous work, some derivatives of 2-aryl-1,3-thiazolidin-4-one were synthesized and assayed for their antimycobacterial and anticancer activity [14]. Herein, we communicate the synthesis and characterization of two series of 2-aryl-4-thiazolidinone derivatives (3 and 4 ) in search of finding potent compounds for cancer treatments. The six chosen thiazolidinone derivatives were assayed for their anticancer activity against various diverse cancer cell lines.

How to cite this article: Güzel-Akdemir Ö, Demir-Yazıcı K. Benzilic acid based new 2-aryl-1,3-thiazolidin-4-one derivatives: synthesis and anticancer activity. J Res Pharm. 2021; 25(3): 305-317. 


\section{RESULTS AND DISCUSSIONS}

\subsection{Chemistry}

The synthetic synthesis pathway of series 3a-p and $\mathbf{4 a - p}$ proceed in three successive steps (Figure 1). The reaction of methyl-2-hydroxy-2,2-diphenylacetate with hydrazine hydrate in the ethanol for six hours resulted in 2-hydroxy-2,2-diphenylacetohydrazide (1). Compound $\mathbf{1}$ refluxed with different aromatic aldehydes for four hours to prepare various phenyl substituted Schiff bases (2). At the third step 2-hydroxy$\mathrm{N}$-(4-oxo-2-substitutedphenyl-1,3-thiazolidin-3-yl)-2,2-diphenylacetamides (3a-p) and 2-hydroxy-N-(5methyl-4-oxo-2-substitutedphenyl-1,3-thiazolidin-3-yl)-2,2-diphenylacetamides (4a-p) were gained from the treatment of 2 with mercaptoacetic acid or 2-mercaptopropionic acid, respectively [14,15].

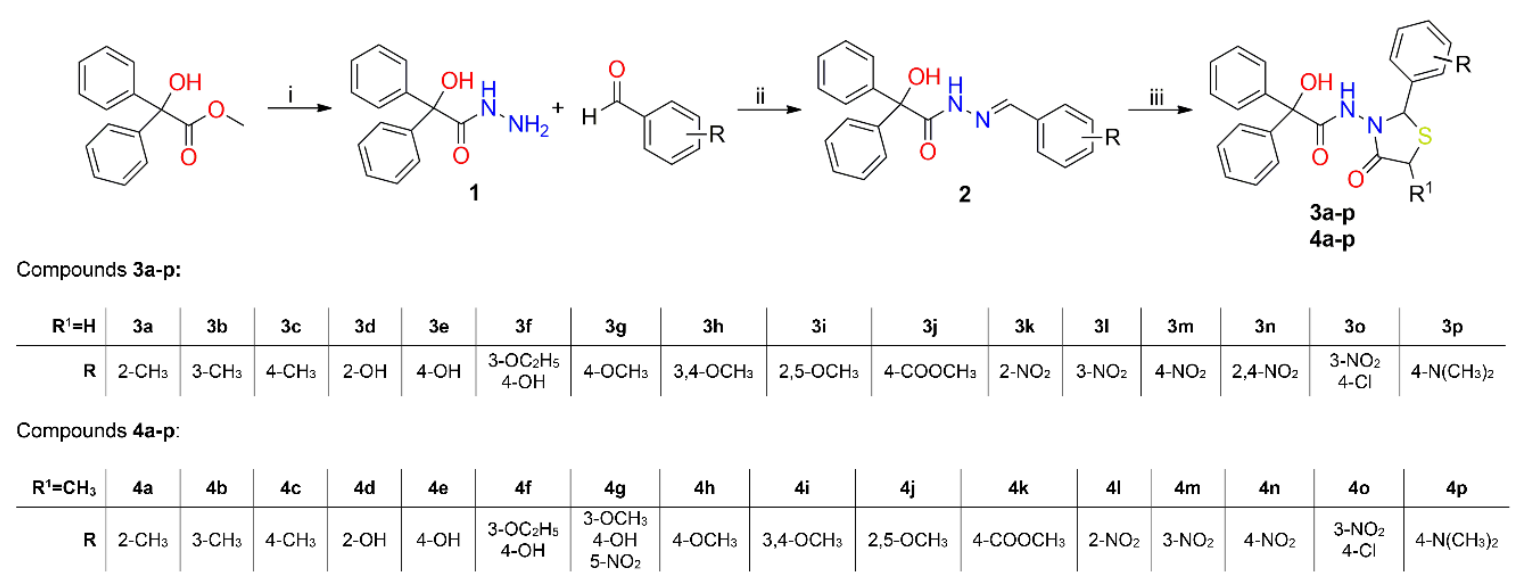

Figure 1. The synthetic procedures for the synthesis of compounds 3 and $\mathbf{4}$ derivatives. Reagents: i) $\mathrm{NH}_{2} \mathrm{NH}_{2} \cdot \mathrm{H}_{2} \mathrm{O}$, ethanol, reflux, 6h; ii) Ethanol, reflux; iii) Mercaptoacetic acid/2-mercaptopropionic acid, dry benzene, reflux, $6 \mathrm{~h}$.

Together with elemental analysis, newly synthesized thiazolidin-4-one based compounds were defined with spectral methods including IR, ${ }^{1} \mathrm{H}-\mathrm{NMR},{ }^{13} \mathrm{C}-\mathrm{NMR}$-APT, ESI-MS (-). Absorption bands for N-H and O$\mathrm{H}$ of the new derivatives were signaled at between $3208-3461 \mathrm{~cm}^{-1}$ in the IR spectra. The stretching vibration of the typical amide $\mathrm{C}=\mathrm{O}$ group was observed between $1661-1687 \mathrm{~cm}^{-1}$, as expected $[15,16]$. In addition, the expected ring closure for 4 -thiazolidinon ring of compounds 3 and 4 is supported by the appearance of the second strong $\mathrm{C}=\mathrm{O}$ stretching bands at $1694-1727 \mathrm{~cm}^{-1}[17,18]$.

${ }^{1} \mathrm{H}-\mathrm{NMR}$ spectral analysis of the compounds 3a-p demonstrated that the $\mathrm{SCH}_{2}$ (methylene) protons of thiazolidinone ring were signaled between $\delta 3.63-3.96$ ppm, as two singlets or doublets. For 4a-p, the $\mathrm{SCHCH}_{3}$ (methine) protons resonated at between 3.85-4.21 ppm, as two quartets. Both observed signals are specific for the protons at 5-position of the 2,3 disubstituted thiazolidin-4-one rings [7]. For both series, peaks exhibited between $\delta$ 5.72-6.81 ppm, $\delta 6.65-6.95 \mathrm{ppm}$, and $\delta$ 10.09-10.46 ppm were ascribed to the $\mathrm{C}_{2}-\mathrm{H}, \mathrm{C}-\mathrm{OH}$, and $\mathrm{CONH}$ protons respectively.[15,19].

${ }^{13} \mathrm{C}$-APT spectra of the new compounds $3 \mathbf{c}, 3 \mathbf{e}, \mathbf{3 f}, \mathbf{4 n}$, and $\mathbf{4 p}$ authenticated the characteristic carbon chemical shifts of the 4-thiazolidinones. Signals of characteristic thiazolidin-4-one $C_{2}, C_{4}$ (lactam $\left.C=O\right), C_{5}(3 \mathbf{a}-$ p) and $C_{5}(4 a-p)$ exhibited at $\delta$ 56.76-62.51, 172.03-172.23, 30.21-30.31 and 38.41-39.31 ppm, respectively [20,21]. Carbon resonances of $\mathrm{C}-\mathrm{OH}$ and $\mathrm{CONH}$ (amide $\mathrm{C}=\mathrm{O}$ ) appeared in the order of $\delta 81.16-81.84$ and 169.16-171.84 $\mathrm{ppm}$. The signals of the aromatic carbons were detected in the expected areas.

APCI(-) mass spectral analysis of $\mathbf{3 c}, \mathbf{3 e}, \mathbf{3} \mathbf{f}, \mathbf{4 n}$, and $\mathbf{4 p}$ revealed molecular ions (M-H)- with greatest relative intensity $(100 \%)$ at $\mathrm{m} / \mathrm{z} 417,419,463,462$ and 460, respectively . This confirmed the molecular weights of the compounds and showed that the expected structures were successfully achieved [22]. It is also obvious that the $\left[(\mathrm{M}-\mathrm{H})-\mathrm{SCH}_{2} \mathrm{CO}\right]^{-}$fragments of the compounds showed the main fragmentation pattern of the 4thiazolidinone system [23]. Detailed spectral data presented in the experimental section.

\subsection{Anticancer activity}

The National Cancer Institute (NCI) determined six of the synthesized compounds, $\mathbf{3 c}, \mathbf{3 g}, \mathbf{3} \mathbf{j}, \mathbf{4} \mathbf{g}, \mathbf{4 n}$, and $4 \mathbf{p}$ to test their possible anticancer activity. To conduct the primary anticancer assays, the Drug Evaluation 
Branch of the National Cancer Institute protocol was applied [24-26]. Using $10^{-5} \mathrm{M}$ single dose in an in vitro analysis, the cytotoxicity and / or the inhibitory features of the new thiazolidin-4-one were measured using 60 different human cancer cell lines originating from 9 neoplastic diseases. For observing the growth percentage, spectrophotometric methods were performed, and for comparison test agents that were used not added to control. The sulphorhodamine B (SRB) test was employed for predicting cell growth/viability estimation and as a procedural method, the drug was exposed continuously for two days.

Non-small cell lung cancer (NSCL), leukemia, CNS cancer, renal, and melanoma cell lines were chosen for screening in the NCI. For individual effects, mean graphs were produced and the variance of every cell line from the total mean value was shown with bars for all the cells studied. The mean of total growth inhibition, expressed in percentage, was evaluated as the center point of the graph. Bars are viewed with a higher inhibition than the average on the right side of the cell lines, while those on the left side have a lower inhibition than the average. In Figure 2-7, single dose Mean Graphs for compounds $3 \mathbf{c}, \mathbf{3 g}, \mathbf{3} \mathbf{j}, \mathbf{4 g}$, $\mathbf{4 n}$, and $\mathbf{4 p}$ for leukemia, CNS, renal, melanoma, and NSCL cancer cell lines are declared respectively.

Against the aforementioned tumour cell lines, the selected compounds showed remarkable inhibition percents (Table 1). Compared with compounds $3 \mathbf{c}$ and $\mathbf{4} \mathbf{p}$, compound $\mathbf{3 g}$ which bearing a methoxy substitution at the para position showed the best but similar antitumor activity for leukemia RPMI-8226 cell lines. Compound $4 \mathbf{p}$ is one of the compounds with high growth inhibition percentage $(72.11 \%)$. Accordingly, a methyl substitution at position 5 of the thiazolidin-4-one ring and a para-dimethylamino group at the phenyl ring seems to be favorable for inhibition of CNS SF-295 cell lines. Compound $4 \mathbf{n}$ also showed good anticancer activity towards to NSCL cancer cell line HOP-92, with an inhibition percent of $67.51 \%$. For compound $4 \mathbf{g}$, which have the best inhibition percent (84.19\%), it was exhibited that combined with a methoxy at position 3 , a hydroxy at position 4 , and nitro at position 5 on the phenyl, a growth of $15.81 \%$ was recorded for a leukemia cell line MOLT-4. (Table 1).

Table 1. In vitro tumor cell growth inhibition of $3 c, 3 g, 3 j, 4 g, 4 n$, and $4 p$.

\begin{tabular}{|c|c|c|c|c|}
\hline Compound & Panel & Cell Line & $\begin{array}{l}\text { Growth } \\
\text { Percent }\end{array}$ & $\begin{array}{c}\text { Inhibition } \\
\text { Percent }\end{array}$ \\
\hline \multirow{4}{*}{$3 c$} & \multirow{2}{*}{ Leukemia } & K-562 & 37.43 & 62.57 \\
\hline & & RPMI-8226 & 59.85 & 40.15 \\
\hline & CNS Cancer & SF-295 & 49.30 & 50.70 \\
\hline & Leukemia & RPMI-8226 & 56.92 & 43.08 \\
\hline \multirow[t]{2}{*}{$3 g$} & NSCL & A549/ATCC & 58.42 & 41.58 \\
\hline & CNS Cancer & SF-295 & 42.89 & 57.00 \\
\hline \multirow{2}{*}{$3 \mathbf{j}$} & Melanoma & SK-MEL-5 & 60.23 & 39.77 \\
\hline & Renal Cancer & A498 & 51.38 & 48.62 \\
\hline \multirow{2}{*}{$4 g$} & \multirow{2}{*}{ Leukemia } & HL-60(TB) & 37.95 & 62.05 \\
\hline & & MOLT-4 & 15.81 & 84.19 \\
\hline \multirow{3}{*}{$4 n$} & NSCL & HOP-92 & 32.49 & 67.51 \\
\hline & CNS Cancer & SF-295 & 43.30 & 56.70 \\
\hline & Leukemia & RPMI-8226 & 60.11 & 39.89 \\
\hline \multirow[t]{2}{*}{$4 p$} & CNS Cancer & SF-295 & 27.89 & 72.11 \\
\hline & Renal Cancer & UO-31 & 47.70 & 52.30 \\
\hline
\end{tabular}

\section{CONCLUSION}

32 new 2-aryl-4-thiazolidinones have been synthesized and some compounds ( $3 \mathbf{c}, 3 \mathbf{g}, 3 \mathbf{j}, \mathbf{4 g}, \mathbf{4 n}$, and $\mathbf{4 p}$ ) were assayed for their antitumor activity against a broad array of cancer cell lines by the NCI. Compound $\mathbf{4 g}$ and $\mathbf{4 p}$, both have 5-methyl substitution at the thiazolidinone ring showed significant antitumor activity with high inhibition percents $(84.19 \%$ and $72.11 \%$, respectively) against different cancer cell lines. The best inhibitory activity observed for $\mathbf{4 g}$ which furnished with 3-methoxy, 4-hydroxy, and 5-nitro substitutions at the 2-phenyl ring. According to the present study, it can be said that derivatives of 2-aryl-1,3-thiazolidin-4-one incorporating benzilic acid present a potential candidate against different cancer cell lines. Further research and modification will be done on compounds $4 \mathrm{~g}$ and $4 \mathrm{p}$ to investigate their relationship with the known therapeutic targets in the studied cancer cell lines. 

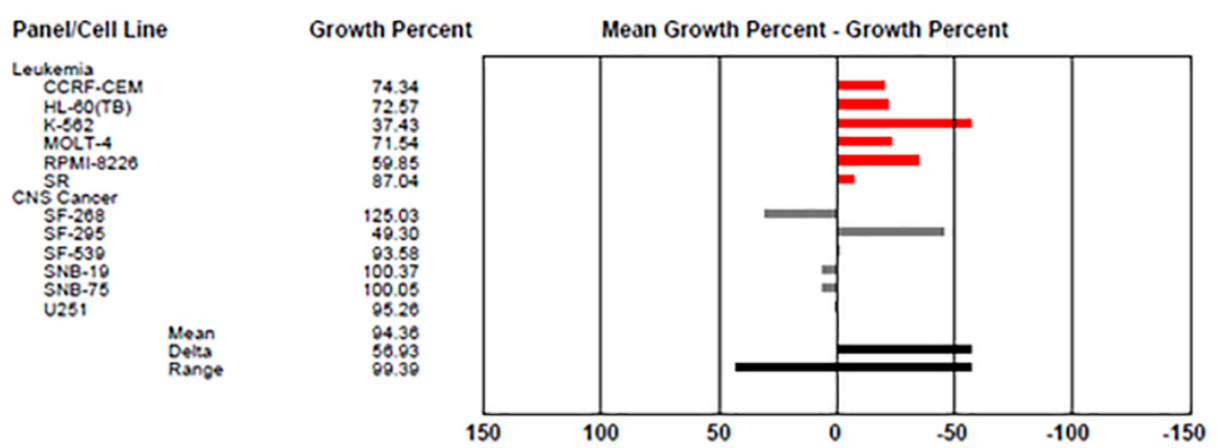

Figure 2. One dose Mean Graph for leukemia and CNS cancer cell lines of 3c.
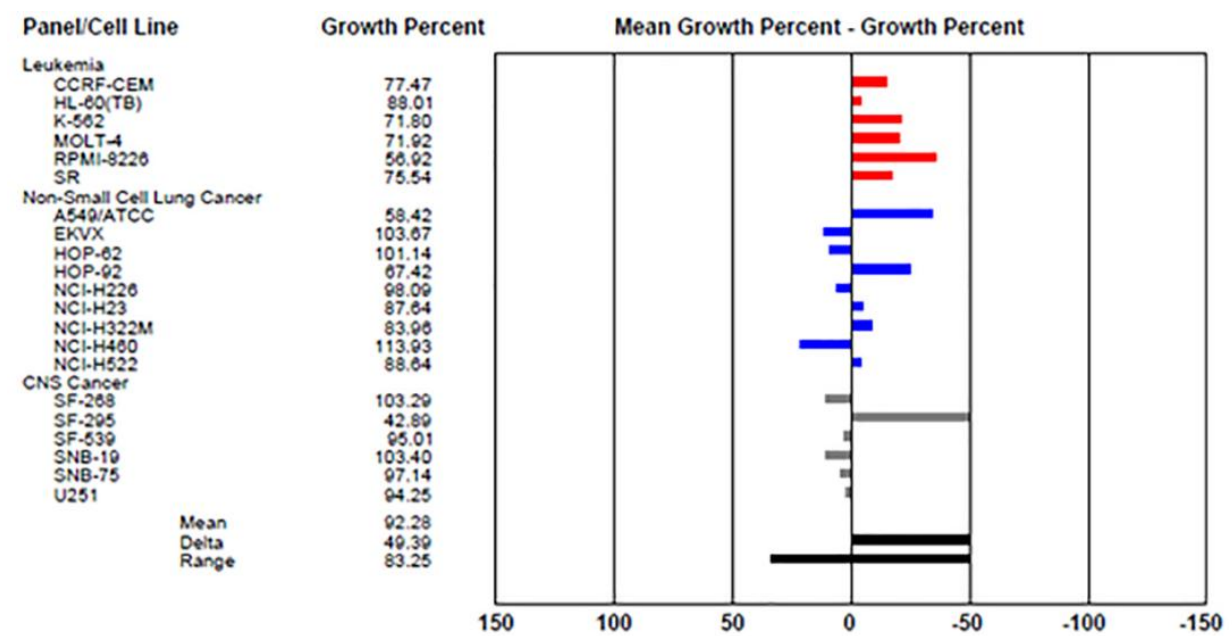

Figure 3. One dose Mean Graph for leukemia, NSCL and CNS cancer cell lines of $\mathbf{3 g}$.
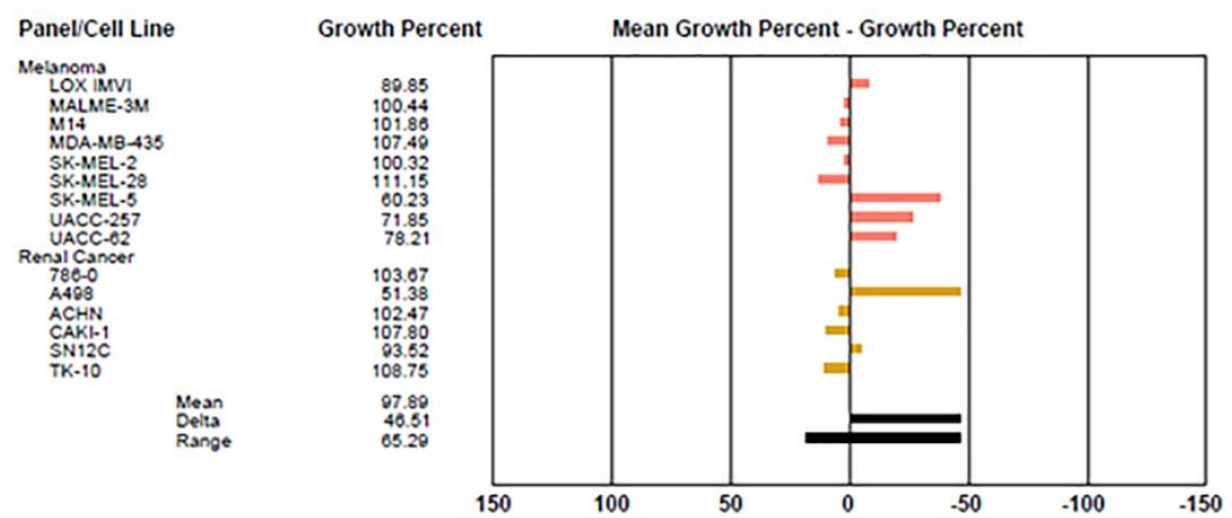

Figure 4. One dose Mean Graph for melanoma and renal cancer cell lines of $\mathbf{3 j}$.

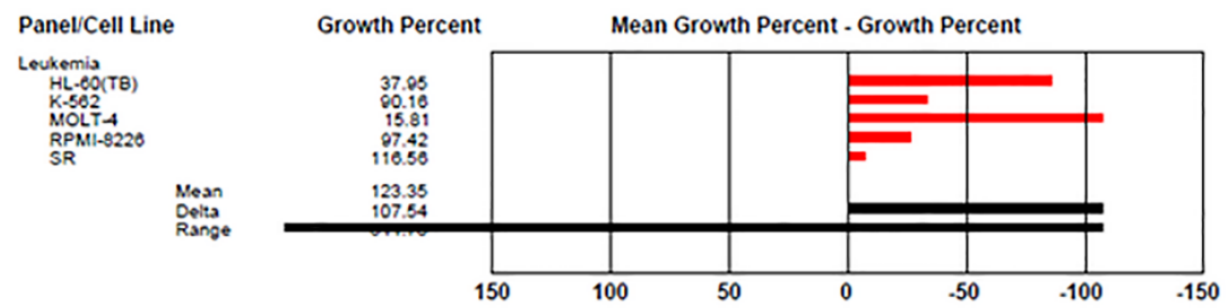

Figure 5. One dose Mean Graph for leukemia cell lines of $\mathbf{4 g}$. 

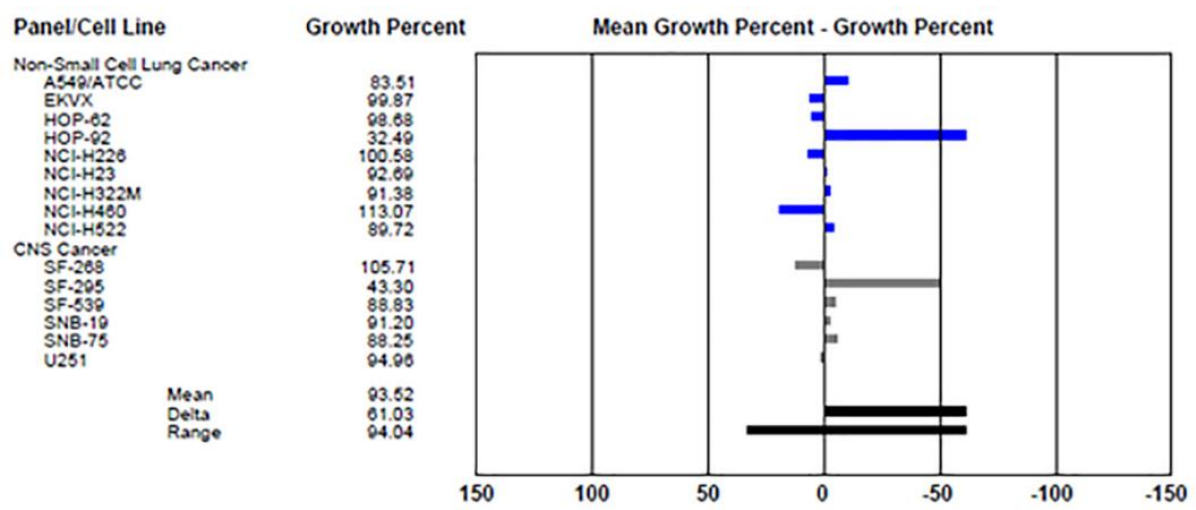

Figure 6. One dose Mean Graph for NSCL and CNS cancer cell lines of $\mathbf{4 n}$.
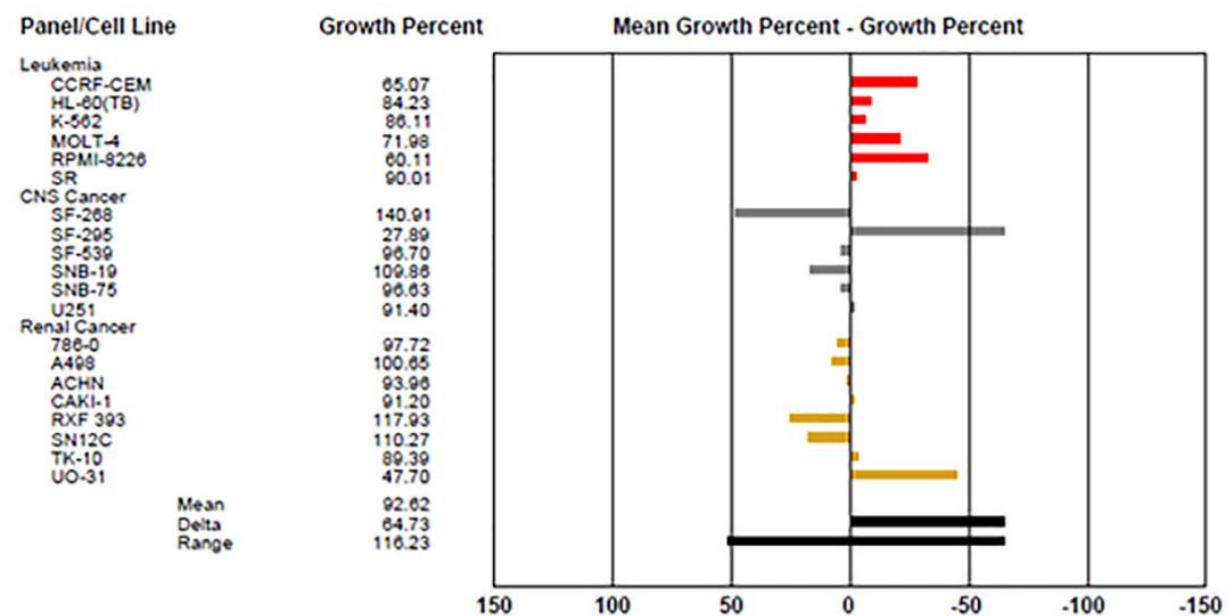

Figure 7. One dose Mean Graph for leukemia, CNS cancer, and renal cancer cell lines of $\mathbf{4} \mathbf{p}$.

\section{MATERIALS AND METHODS}

\subsection{Chemistry}

Melting points measurement was conducted with Buchi 540 apparatus by an open capillary method. TLC was carried out to verify the purity of the synthesized compounds. Infrared spectral analyses of the compounds were conducted with KBr disk using Perkin-Elmer 1600 FTIR. The observed values were recorded as $\mathrm{v}_{\max } \mathrm{cm}^{-1}$. The $500 \mathrm{MHz}$ NMR Varian Unity INOVA Spectrometer was used to conduct ${ }^{1} \mathrm{H}-\mathrm{NMR}$ and ${ }^{13} \mathrm{C}-$ NMR(APT) analyses using TMS as reference and DMSO- $d_{6}$ as the solvent and all the signals observed are expressed in ppm. Thermo Finnigan Flash EA 1112 was used to conduct the elemental analysis $(\mathrm{C}, \mathrm{H}, \mathrm{N})$ of the novel compounds and the results were found to be in $\pm 0.4 \%$. Mass spectral data (LC/MS-ESI) were measured with Finnigan Trace DSQ Mass Spectrometer.

\subsubsection{Synthesis of 2-hydroxy-2,2-diphenylacetohydrazide (1)}

2-hydroxy-2,2-diphenylacetic acid ester $(0.05 \mathrm{~mol})$ was refluxed with $12 \mathrm{ml}$ of hydrazine hydrate for 12 h. After the reaction was completed, it was poured into a crystallizing dish and left open. The crystals formed thereof were further recrystallized from $\mathrm{C}_{2} \mathrm{H}_{5} \mathrm{OH}[27,28]$.

5.1.2. General procedure for preparation of 2-hydroxy-2,2-diphenyl-N'-[(substituted phenyl)methylene]acetohydrazides (2)

A solution of compound $1(6 \mathrm{mmol})$ in ethyl alcohol $(30 \mathrm{~mL})$ was refluxed with a suitable aromatic aldehyde $(6.6 \mathrm{mmol})$ for $4 \mathrm{~h}$. The obtained raw precipitate was recrystallized from/washed with ethyl alcohol to yield the desired clean compounds [27-30]. 
5.1.3. General procedure for preparation of 2-hydroxy-N-(4-oxo-2-substitutedphenyl-1,3-thiazolidin-3-yl)-2,2diphenylacetamide/2-Hydroxy-N-(5-methyl-4-oxo-2-substitutedphenyl-1,3-thiazolidin-3-yl)-2,2-diphenylacetamides $(3 a-p$ and $4 a-p)$

With a Dean-Stark trap, $5 \mathrm{mmol}$ of the purified compound 2 was suspended in dry benzene (30 ml) and refluxed for $6 \mathrm{~h}$ with $5 \mathrm{eq}$ of either mercaptoacetic acid or 2-mercaptopropionic acid. Evaporation of excess benzene is done in vacuo. By using saturated $\mathrm{NaHCO}_{3}$ solution, the gained residue was triturated until $\mathrm{CO}_{2}$ evolution stopped and refrigerated at night. The yielded product washed with $\mathrm{H}_{2} \mathrm{O}$, dried, and purified by recrystallization from ethyl alcohol or water [14].

N-[2-(2-methylphenyl)-4-oxo-1,3-thiazolidin-3-yl]-2-hydroxy-2,2-diphenylacetamide (3a)

Yield 63\%; M.p.: 192-193 ${ }^{\circ} \mathrm{C}$; IR (KBr) ( $\left.\overline{\boldsymbol{\nu}}, \mathrm{cm}^{-1}\right): 3275(\mathrm{O}-\mathrm{H} / \mathrm{N}-\mathrm{H}), 1679,1711$ (C=O); ${ }^{1} \mathrm{H}-\mathrm{NMR}$ (DMSO$\left.d_{6}, 500 \mathrm{MHz}\right) \delta(\mathrm{ppm}): 2.16\left(3 \mathrm{H}, \mathrm{s}, 2-\mathrm{CH}_{3}\right), 3.73,3.82\left(2 \mathrm{H}, 2 \mathrm{~d}, J=16.10 \mathrm{~Hz}\right.$, thiazolidine $\left.\mathrm{C}_{5}-\mathrm{H}\right), 6.10(1 \mathrm{H}, \mathrm{s}$, thiazolidine $\left.\mathrm{C}_{2}-\mathrm{H}\right), 6.71(1 \mathrm{H}, \mathrm{s}, \mathrm{C}-\mathrm{OH}), 7.13(1 \mathrm{H}, \mathrm{d}, \mathrm{J}=7.81 \mathrm{~Hz}, \mathrm{Ar}-\mathrm{H}), 7.19-7.27(12 \mathrm{H}, \mathrm{m}, \mathrm{Ar}-\mathrm{H}), 7.58(1 \mathrm{H}, \mathrm{d}$, $J=4.88 \mathrm{~Hz}, \mathrm{Ar}-\mathrm{H}), 10.29(1 \mathrm{H}, \mathrm{s}, \mathrm{CONH})$. Anal. Calcd. for $\mathrm{C}_{24} \mathrm{H}_{22} \mathrm{~N}_{2} \mathrm{O}_{3} \mathrm{~S}$ (418.51): C, 68.88; H, 5.30; N, 6.69. Found: C, 68.79; H, 5.53; N, 6.53 .

\section{N-[2-(3-Methylphenyl)-4-oxo-1,3-thiazolidin-3-yl]-2-hydroxy-2,2-diphenylacetamide (3b)}

Yield 62\%; M.p.: 189-190 ㄷ; IR (KBr) ( $\left.\bar{\nu}, \mathrm{cm}^{-1}\right): 3280(\mathrm{O}-\mathrm{H} / \mathrm{N}-\mathrm{H}), 1675,1711$ (C=O); ${ }^{1} \mathrm{H}-\mathrm{NMR}$ (DMSO$\left.d_{6}, 500 \mathrm{MHz}\right) \delta(\mathrm{ppm}): 2.26\left(3 \mathrm{H}, \mathrm{s}, 3-\mathrm{CH}_{3}\right), 3.69,3.82\left(2 \mathrm{H}, 2 \mathrm{~d}, \mathrm{~J}=16.11 \mathrm{~Hz}\right.$, thiazolidine $\left.\mathrm{C}_{5}-\mathrm{H}\right), 5.79(1 \mathrm{H}, \mathrm{s}$, thiazolidine $\left.\mathrm{C}_{2}-\mathrm{H}\right), 6.71(1 \mathrm{H}, \mathrm{s}, \mathrm{C}-\mathrm{OH}), 7.11-7.17(3 \mathrm{H}, \mathrm{m}, \mathrm{Ar}-\mathrm{H}), 7.20-7.27(11 \mathrm{H}, \mathrm{m}, \mathrm{Ar}-\mathrm{H}), 10.22(1 \mathrm{H}, \mathrm{s}, \mathrm{CONH})$. Anal. Calcd. for $\mathrm{C}_{24} \mathrm{H}_{22} \mathrm{~N}_{2} \mathrm{O}_{3} \mathrm{~S}$ (418.51): C, 68.88; H, 5.30; N, 6.69. Found: C, 68.62; H, 5.42; N, 6.62.

N-[2-(4-Methylphenyl)-4-oxo-1,3-thiazolidin-3-yl]-2-hydroxy-2,2-diphenylacetamide (3c)

Yield 56\%; M.p.: $217-218{ }^{\circ} \mathrm{C}$; IR (KBr) ( $\left.\bar{\nu}, \mathrm{cm}^{-1}\right): 3284(\mathrm{O}-\mathrm{H} / \mathrm{N}-\mathrm{H}), 1680,1714$ (C=O); ${ }^{1} \mathrm{H}-\mathrm{NMR}$ (DMSO$\left.d_{6}, 500 \mathrm{MHz}\right) \delta$ (ppm): $2.32\left(3 \mathrm{H}, \mathrm{s}, 4-\mathrm{CH}_{3}\right), 3.69,3.82\left(2 \mathrm{H}, 2 \mathrm{dd}, \mathrm{J}=15.62,1.46 \mathrm{~Hz}\right.$, thiazolidine $\left.\mathrm{C}_{5}-\mathrm{H}\right), 5.78(1 \mathrm{H}, \mathrm{s}$, thiazolidine $\left.\mathrm{C}_{2}-\mathrm{H}\right), 6.69(1 \mathrm{H}, \mathrm{s}, \mathrm{C}-\mathrm{OH}), 7.10\left(4 \mathrm{H}, \mathrm{d}, \mathrm{J}=7.81 \mathrm{~Hz}\right.$, 4-methylphenyl $\left.\mathrm{C}_{2,3,5,6}-\mathrm{H}\right), 7.18-7.24$ (5H, m, ArH), 7.25-7.27 (3H, m, Ar-H), $7.30(2 \mathrm{H}, \mathrm{d}, \mathrm{J}=8.30 \mathrm{~Hz}, \mathrm{Ar}-\mathrm{H}), 10.20$ (1H, s, CONH); 13C-NMR (APT) (DMSO$\left.d_{6} / 125 \mathrm{MHz}\right) \delta(\mathrm{ppm}): 21.54\left(\mathrm{CH}_{3}\right), 30.21\left(\mathrm{C}_{5}\right), 62.42\left(\mathrm{C}_{2}\right), 81.23(\mathrm{C}-\mathrm{OH}), 127.94,127.99,128.15,128.28,128.94$, 129.53 (ar. CH), 135.18, 139.05, 144.12, 144.16 (ar. C), 169.27 (amide $C=O), 172.06$ (lactam C=O); LC/MS: $m / z$ $417(\mathrm{M}-\mathrm{H})^{-}$. Anal. Calcd. for $\mathrm{C}_{24} \mathrm{H}_{22} \mathrm{~N}_{2} \mathrm{O}_{3} \mathrm{~S}$ (418.51): C, 68.88; H, 5.30; N, 6.69. Found: C, 68.50; H, 5.45; N, 6.62.

N-[2-(2-Hydroxyphenyl)-4-oxo-1,3-thiazolidin-3-yl]-2-hydroxy-2,2-diphenylacetamide (3d)

Yield 37\%; M.p.: $226-228^{\circ} \mathrm{C}$; IR (KBr) ( $\left.\bar{\nu}, \mathrm{cm}^{-1}\right): 3308(\mathrm{O}-\mathrm{H} / \mathrm{N}-\mathrm{H}), 1678,1711$ (C=O); ${ }^{1} \mathrm{H}-\mathrm{NMR}$ (DMSO$\left.d_{6}, 500 \mathrm{MHz}\right) \delta(\mathrm{ppm}): 3.63,3.76\left(2 \mathrm{H}, 2 \mathrm{dd}, J=16.11,1.95 \mathrm{~Hz}\right.$, thiazolidine $\left.\mathrm{C}_{5}-\mathrm{H}\right), 6.16\left(1 \mathrm{H}\right.$, s, thiazolidine $\left.\mathrm{C}_{2}-\mathrm{H}\right)$, 6.75 (1H, s, C-OH), 6.77-6.78 (2H, m, 2-hydroxyphenyl C3,5-H), $7.14(1 \mathrm{H}, \mathrm{td}, J=7.32,1.95 \mathrm{~Hz}, 2$-hydroxyphenyl $\left.\mathrm{C}_{4}-\mathrm{H}\right), 7.22-7.33(11 \mathrm{H}, \mathrm{m}, \mathrm{Ar}-\mathrm{H}), 9.85(1 \mathrm{H}, \mathrm{s}, 2-\mathrm{OH}), 10.19(1 \mathrm{H}, \mathrm{s}, \mathrm{CONH})$. Anal. Calcd. for $\mathrm{C}_{23} \mathrm{H}_{20} \mathrm{~N}_{2} \mathrm{O}_{4} \mathrm{~S}(420.48)$ : C, 65.70; H, 4.79; N, 6.66. Found: C, 65.50; H, 4.56; N, 7.02.

N-[2-(4-Hydroxyphenyl)-4-oxo-1,3-thiazolidin-3-yl]-2-hydroxy-2,2-diphenylacetamide (3e)

Yield 29\%; M.p.: 223-224 ${ }^{\circ} \mathrm{C}$; IR (KBr) ( $\left.\bar{\nu}, \mathrm{cm}^{-1}\right): 3243(\mathrm{O}-\mathrm{H} / \mathrm{N}-\mathrm{H}), 1665,1694$ (C=O); ${ }^{1 H}-\mathrm{NMR}$ (DMSO$\left.d_{6}, 500 \mathrm{MHz}\right) \delta$ (ppm): 3.68, $3.77\left(2 \mathrm{H}, 2 \mathrm{dd}, J=16.11,1.95 \mathrm{~Hz}\right.$, thiazolidine $\left.\mathrm{C}_{5}-\mathrm{H}\right), 5.72\left(1 \mathrm{H}\right.$, s, thiazolidine $\left.\mathrm{C}_{2}-\mathrm{H}\right)$, $6.68(1 \mathrm{H}, \mathrm{s}, \mathrm{C}-\mathrm{OH}), 6.70\left(2 \mathrm{H}, \mathrm{dd}, J=6.84,1.95 \mathrm{~Hz}\right.$, 4-hydroxyphenyl $\left.\mathrm{C}_{3,5}-\mathrm{H}\right), 7.07$ (2H, brs, 4-hydroxyphenyl $\mathrm{C}_{2,6^{-}}$ H), 7.20-7.25 (7H, m, Ar-H), 7.26-7.28 (3H, m, Ar-H), 9.60 (1H, s, 4-OH), 10.12 (1H, s, CONH); ${ }^{13} \mathrm{C}-\mathrm{NMR}(\mathrm{APT})$ $\left(\mathrm{DMSO}-d_{6} / 125 \mathrm{MHz}\right) \delta(\mathrm{ppm}): 30.27\left(\mathrm{C}_{5}\right), 62.51\left(\mathrm{C}_{2}\right), 81.27(\mathrm{C}-\mathrm{OH}), 115.72,127.86,127.97,127.99,128.10,128.14$, 128.36, 130.61 (ar. CH), 144.10, 144.23 (ar. C), 158.86 (ar. C-OH), 169.16 (amide C=O), 172.03 (lactam C=O); LC/MS: $m / z 419$ (M-H)- Anal. Calcd. for $\mathrm{C}_{23} \mathrm{H}_{20} \mathrm{~N}_{2} \mathrm{O}_{4} \mathrm{~S}$ (420.48): C, 65.70; H, 4.79; N, 6.66. Found: C, 65.51; H, $5.00 ; \mathrm{N}, 6.68$.

N-[2-(3-Ethoxy-4-hydroxyphenyl)-4-oxo-1,3-thiazolidin-3-yl]-2-hydroxy-2,2-diphenylacetamide (3f)

Yield 51\%; M.p.: 198-200 ${ }^{\circ} \mathrm{C}$; IR (KBr) ( $\left.\bar{\nu}, \mathrm{cm}^{-1}\right): 3347$ (O-H/N-H), 1673, 1712 (C=O); ${ }^{1} \mathrm{H}-\mathrm{NMR}$ (DMSO$\left.d_{6}, 500 \mathrm{MHz}\right) \delta$ (ppm): $1.30\left(3 \mathrm{H}, \mathrm{t}, J=6.83 \mathrm{~Hz}, 3-\mathrm{OCH}_{2} \mathrm{CH}_{3}\right), 3.87-3.96\left(2 \mathrm{H}, \mathrm{m}, 3-\mathrm{OCH}_{2} \mathrm{CH}_{3}\right), 3.68,3.78(2 \mathrm{H}, 2 \mathrm{~d}$, $J=15.62 \mathrm{~Hz}$, thiazolidine $\left.\mathrm{C}_{5}-\mathrm{H}\right), 5.76\left(1 \mathrm{H}, \mathrm{s}\right.$, thiazolidine $\left.\mathrm{C}_{2}-\mathrm{H}\right), 6.71(1 \mathrm{H}, \mathrm{d}, J=7.81 \mathrm{~Hz}, \mathrm{C}-\mathrm{OH}), 7.01(1 \mathrm{H}, \mathrm{d}, J=1.95$ $\mathrm{Hz}, \mathrm{Ar}-\mathrm{H}), 7.13$ (2H, brs, Ar-H), 7.22-7.25 (4H, m, Ar-H), 7.27 (6H, s, Ar-H), 9.04 (1H, brs, Ar-OH), 10.16 (1H, $\mathrm{s}, \mathrm{CONH}) ;{ }^{13} \mathrm{C}-\mathrm{NMR}(\mathrm{APT})\left(\mathrm{DMSO}-d_{6} / 125 \mathrm{MHz}\right) \delta(\mathrm{ppm}): 15.43\left(\mathrm{OCH}_{2} \mathrm{CH}_{3}\right), 30.31\left(\mathrm{C}_{5}\right), 56.76\left(\mathrm{C}_{2}\right), 64.42$ $\left(\mathrm{OCH}_{2} \mathrm{CH}_{3}\right), 81.27(\mathrm{C}-\mathrm{OH}), 115.51,121.96,128.01,128.15,128.29$ (ar. CH), 144.15, 144.23 (ar. C), 147.47, 148.34 
(ar. C-OR), 169.23 (amide C=O), 172.05 (lactam C=O); LC/MS: $\mathrm{m} / z 463$ (M-H)-. Anal. Calcd. for $\mathrm{C}_{25} \mathrm{H}_{24} \mathrm{~N}_{2} \mathrm{O}_{5} \mathrm{~S}$ (464.53): C, 64.64; H, 5.21; N, 6.03. Found: C, 64.34; H, 5.38; N, 5.92.

$\mathrm{N}$-[2-(4-Methoxyphenyl)-4-oxo-1,3-thiazolidin-3-yl]-2-hydroxy-2,2-diphenylacetamide (3g)

Yield 68\%; M.p.: 158-159 ${ }^{\circ} \mathrm{C}$; IR (KBr) ( $\left.\bar{\nu}, \mathrm{cm}^{-1}\right): 3276$ (O-H/N-H), 1673, 1714 (C=O); ${ }^{1} \mathrm{H}-\mathrm{NMR}$ (DMSO$\left.d_{6}, 500 \mathrm{MHz}\right) \delta(\mathrm{ppm}): 3.77\left(3 \mathrm{H}, \mathrm{s}, 4-\mathrm{OCH}_{3}\right), 3.69,3.80\left(2 \mathrm{H}, 2 \mathrm{dd}, J=15.62,1.46 \mathrm{~Hz}\right.$, thiazolidine $\left.\mathrm{C}_{5}-\mathrm{H}\right), 5.79(1 \mathrm{H}$, s, thiazolidine $\left.\mathrm{C}_{2}-\mathrm{H}\right), 6.69(1 \mathrm{H}, \mathrm{s}, \mathrm{C}-\mathrm{OH}), 6.86\left(2 \mathrm{H}, \mathrm{dd}, \mathrm{J}=8.79,1.95 \mathrm{~Hz}, 4\right.$-methoxyphenyl $\left.\mathrm{C}_{3,5}-\mathrm{H}\right), 7.08(2 \mathrm{H}, \mathrm{d}$, $J=5.86 \mathrm{~Hz}, \mathrm{Ar}-\mathrm{H}), 7.19(2 \mathrm{H}, \mathrm{t}, J=7.32 \mathrm{~Hz}, \mathrm{Ar}-\mathrm{H}), 7.22-7.28(6 \mathrm{H}, \mathrm{m}, \mathrm{Ar}-\mathrm{H}), 7.34(2 \mathrm{H}, \mathrm{d}, J=8.79 \mathrm{~Hz}, 4-$ methoxyphenyl $\left.\mathrm{C}_{2,6}-\mathrm{H}\right), 10.17(1 \mathrm{H}, \mathrm{s}, \mathrm{CONH})$. Anal. Calcd. for $\mathrm{C}_{24} \mathrm{H}_{22} \mathrm{~N}_{2} \mathrm{O}_{4} \mathrm{~S}(434.51)$ : C, 66.34; $\mathrm{H}, 5.10 ; \mathrm{N}, 6.45$. Found: C, 66.38; H, 5.52; N, 6.15 .

\section{N-[2-(3,4-Dimethoxyphenyl)-4-oxo-1,3-thiazolidin-3-yl]-2-hydroxy-2,2-diphenylacetamide (3h)}

Yield 61\%; M.p.: 115-116 C; IR (KBr) ( $\left.\overline{\boldsymbol{\nu}}, \mathrm{cm}^{-1}\right): 3303$ (O-H/N-H), 1676, 1698 (C=O); ${ }^{1} \mathrm{H}-\mathrm{NMR}$ (DMSO$\left.d_{6}, 500 \mathrm{MHz}\right) \delta(\mathrm{ppm}): 3.67\left(3 \mathrm{H}, \mathrm{s}, \mathrm{OCH}_{3}\right), 3.76\left(3 \mathrm{H}, \mathrm{s}, \mathrm{OCH}_{3}\right), 3.69,3.80(2 \mathrm{H}, 2 \mathrm{dd}, J=16.11,1.46 \mathrm{~Hz}$, thiazolidine $\left.\mathrm{C}_{5}-\mathrm{H}\right), 5.80\left(1 \mathrm{H}, \mathrm{s}\right.$, thiazolidine $\left.\mathrm{C}_{2}-\mathrm{H}\right), 6.71(1 \mathrm{H}, \mathrm{s}, \mathrm{C}-\mathrm{OH}), 6.84\left(1 \mathrm{H}, \mathrm{d}, \mathrm{J}=8.30 \mathrm{~Hz}, 3,4\right.$-dimethoxyphenyl $\left.\mathrm{C}_{5}-\mathrm{H}\right)$, $6.88\left(1 \mathrm{H}, \mathrm{dd}, J=8.30,1.95 \mathrm{~Hz}, 3\right.$,4-dimethoxyphenyl $\left.\mathrm{C}_{6}-\mathrm{H}\right), 7.06\left(1 \mathrm{H}, \mathrm{d}, J=1.95 \mathrm{~Hz}, 3\right.$, 4-dimethoxyphenyl $\left.\mathrm{C}_{2}-\mathrm{H}\right)$, $7.20(2 \mathrm{H}, \mathrm{t}, J=6.83 \mathrm{~Hz}, \mathrm{Ar}-\mathrm{H}), 7.22-7.27(7 \mathrm{H}, \mathrm{m}, \mathrm{Ar}-\mathrm{H}), 10.23(1 \mathrm{H}, \mathrm{s}, \mathrm{CONH})$. Anal. Calcd. for $\mathrm{C}_{25} \mathrm{H}_{24} \mathrm{~N}_{2} \mathrm{O}_{5} \mathrm{~S}$ (464.54): C, 64.64; H, 5.21; N, 6.03. Found: C, 64.35; H, 5.69; N, 5.79.

N-[2-(2,5-Dimethoxyphenyl)-4-oxo-1,3-thiazolidin-3-yl]-2-hydroxy-2,2-diphenylacetamide (3i)

Yield 62\%; M.p.: 177-178 C; IR (KBr) ( $\left.\bar{\nu}, \mathrm{cm}^{-1}\right): 3303$ (O-H/N-H), 1676, 1698 (C=O); ${ }^{1} \mathrm{H}-\mathrm{NMR}$ (DMSO$\left.d_{6}, 500 \mathrm{MHz}\right) \delta(\mathrm{ppm}): 3.67\left(3 \mathrm{H}, \mathrm{s}, \mathrm{OCH}_{3}\right), 3.69\left(3 \mathrm{H}, \mathrm{s}, \mathrm{OCH}_{3}\right), 3.78,3.82\left(2 \mathrm{H}, 2 \mathrm{~d}, \mathrm{~J}=1.70 \mathrm{~Hz}\right.$, thiazolidine $\left.\mathrm{C}_{5}-\mathrm{H}\right)$, $6.15\left(1 \mathrm{H}, \mathrm{s}\right.$, thiazolidine $\left.\mathrm{C}_{2}-\mathrm{H}\right), 6.77(1 \mathrm{H}, \mathrm{s}, \mathrm{COH}), 6.85(1 \mathrm{H}, \mathrm{dd}, J=9.03,3.17 \mathrm{~Hz}, \mathrm{Ar}-\mathrm{H}), 6.93(1 \mathrm{H}, \mathrm{d}, J=9.28 \mathrm{~Hz}$, Ar-H), $7.18(1 \mathrm{H}, \mathrm{d}, \mathrm{J}=3.42 \mathrm{~Hz}, \mathrm{Ar}-\mathrm{H}), 7.26-7.29(10 \mathrm{H}, \mathrm{m}, \mathrm{Ar}-\mathrm{H}), 10.36(1 \mathrm{H}, \mathrm{s}, \mathrm{CONH})$. Anal. Calcd. for $\mathrm{C}_{25} \mathrm{H}_{24} \mathrm{~N}_{2} \mathrm{O}_{5} \mathrm{~S}$ (464.54): C, 64.64; $\mathrm{H}, 5.21 ; \mathrm{N}, 6.03$. Found: $\mathrm{C}, 64.20 ; \mathrm{H}, 5.55 ; \mathrm{N}, 5.96$.

\section{N-[2-(4-Methoxycarbonylphenyl)-4-oxo-1,3-thiazolidin-3-yl]-2-hydroxy-2,2-diphenylacetamide (3j)}

Yield 61\%; M.p.: 151-152 ${ }^{\circ} \mathrm{C}$; IR (KBr) $\left(\bar{\nu}, \mathrm{cm}^{-1}\right): 3333$ (O-H/N-H), 1672, 1722 (C=O); ${ }^{1} \mathrm{H}-\mathrm{NMR}$ (DMSO$\left.d_{6}, 500 \mathrm{MHz}\right) \delta$ (ppm): $3.88\left(3 \mathrm{H}, \mathrm{s}, 4-\mathrm{COOCH}_{3}\right), 3.74,3.90\left(2 \mathrm{H}, 2 \mathrm{dd}, J=15.13,1.46 \mathrm{~Hz}\right.$, thiazolidine $\left.\mathrm{C}_{5}-\mathrm{H}\right), 5.89$ $\left(1 \mathrm{H}, \mathrm{s}\right.$, thiazolidine $\left.\mathrm{C}_{2}-\mathrm{H}\right), 6.72(1 \mathrm{H}, \mathrm{s}, \mathrm{C}-\mathrm{OH}), 7.09(2 \mathrm{H}, \mathrm{d}, J=7.32 \mathrm{~Hz}, \mathrm{Ar}-\mathrm{H}), 7.17(2 \mathrm{H}, \mathrm{t}, J=6.83 \mathrm{~Hz}, \mathrm{Ar}-\mathrm{H}), 7.20-$ $7.23(3 \mathrm{H}, \mathrm{m}, \mathrm{Ar}-\mathrm{H}), 7.24-7.26(3 \mathrm{H}, \mathrm{m}, \mathrm{Ar}-\mathrm{H}), 7.56\left(2 \mathrm{H}, \mathrm{d}, \mathrm{J}=8.30 \mathrm{~Hz}, 4\right.$-methoxycarbonylphenyl $\left.\mathrm{C}_{2,6}-\mathrm{H}\right), 7.86(2 \mathrm{H}$, d, $J=8.79 \mathrm{~Hz}$, 4-methoxycarbonylphenyl $\left.\mathrm{C}_{3,5}-\mathrm{H}\right), 10.34(1 \mathrm{H}, \mathrm{s}, \mathrm{CONH})$. Anal. Calcd. for $\mathrm{C}_{25} \mathrm{H}_{22} \mathrm{~N}_{2} \mathrm{O}_{5} \mathrm{~S}(462.52)$ : C, 64.92; H, 4.79; N, 6.06. Found: C, 64.99; H, 4.72; N, 6.10.

$\mathrm{N}$-[2-(2-Nitrophenyl)-4-oxo-1,3-thiazolidin-3-yl]-2-hydroxy-2,2-diphenylacetamide (3k)

Yield 32\%; M.p.: 208-209 ${ }^{\circ} \mathrm{C}$; IR (KBr) ( $\left.\bar{\nu}, \mathrm{cm}^{-1}\right): 3303,3493$ (O-H/N-H), 1674, 1719 (C=O); ${ }^{1} \mathrm{H}-\mathrm{NMR}$ (DMSO- $\left.d_{6}, 500 \mathrm{MHz}\right) \delta(\mathrm{ppm}): 3.70,3.92\left(2 \mathrm{H}, 2 \mathrm{~d}, J=15.62 \mathrm{~Hz}\right.$, thiazolidine $\left.\mathrm{C}_{5}-\mathrm{H}\right), 6.17\left(1 \mathrm{H}, \mathrm{s}\right.$, thiazolidine $\mathrm{C}_{2-}$ $\mathrm{H}), 6.79(1 \mathrm{H}, \mathrm{s}, \mathrm{C}-\mathrm{OH}), 7.16-7.19(2 \mathrm{H}, \mathrm{m}, \mathrm{Ar}-\mathrm{H}), 7.20-7.25(8 \mathrm{H}, \mathrm{m}, \mathrm{Ar}-\mathrm{H}), 7.60(1 \mathrm{H}, \mathrm{t}, \mathrm{J}=7.81 \mathrm{~Hz}$, 2-nitrophenyl $\left.\mathrm{C}_{4}-\mathrm{H}\right), 7.73\left(1 \mathrm{H}, \mathrm{t}, J=7.81 \mathrm{~Hz}\right.$, 2-nitrophenyl $\left.\mathrm{C}_{6}-\mathrm{H}\right), 8.00\left(2 \mathrm{H}, \mathrm{t}, J=8.30 \mathrm{~Hz}\right.$, 2-nitrophenyl $\left.\mathrm{C}_{3,5}-\mathrm{H}\right), 10.46(1 \mathrm{H}, \mathrm{s}$, $\mathrm{CONH}$ ). Anal. Calcd. for $\mathrm{C}_{23} \mathrm{H}_{19} \mathrm{~N}_{3} \mathrm{O}_{5} \mathrm{~S}$ (449.48): $\mathrm{C}, 61.46 ; \mathrm{H}, 4.26 ; \mathrm{N}, 9.35$. Found: $\mathrm{C}, 61.13 ; \mathrm{H}, 4.09 ; \mathrm{N}, 8.99$.

N-[2-(3-Nitrophenyl)-4-oxo-1,3-thiazolidin-3-yl]-2-hydroxy-2,2-diphenylacetamide (3l)

Yield 78\%; M.p.: 185-186 ${ }^{\circ} \mathrm{C}$; IR (KBr) ( $\left.\bar{\nu}, \mathrm{cm}^{-1}\right): 3366$ (O-H/N-H), 1680, 1728 (C=O); ${ }^{1} \mathrm{H}-\mathrm{NMR}$ (DMSO$\left.d_{6}, 500 \mathrm{MHz}\right) \delta(\mathrm{ppm}): 3.76,3.95\left(2 \mathrm{H}, 2 \mathrm{dd}, J=15.62,1.46 \mathrm{~Hz}\right.$, thiazolidine $\left.\mathrm{C}_{5}-\mathrm{H}\right), 5.94\left(1 \mathrm{H}, \mathrm{s}\right.$, thiazolidine $\left.\mathrm{C}_{2}-\mathrm{H}\right)$, $6.74(1 \mathrm{H}, \mathrm{s}, \mathrm{C}-\mathrm{OH}), 7.08(2 \mathrm{H}, \mathrm{d}, J=7.32 \mathrm{~Hz}, \mathrm{Ar}-\mathrm{H}), 7.16(2 \mathrm{H}, \mathrm{t}, J=6.83 \mathrm{~Hz}, \mathrm{Ar}-\mathrm{H}), 7.19-7.26(6 \mathrm{H}, \mathrm{m}, \mathrm{Ar}-\mathrm{H}), 7.56$ $\left(1 \mathrm{H}, \mathrm{t}, J=7.81 \mathrm{~Hz}, 3\right.$-nitrophenyl $\left.\mathrm{C}_{5}-\mathrm{H}\right), 7.87\left(1 \mathrm{H}, \mathrm{dd}, J=7.81,1.46 \mathrm{~Hz}, 3\right.$-nitrophenyl $\left.\mathrm{C}_{6}-\mathrm{H}\right), 8.15(1 \mathrm{H}, \mathrm{dd}, J=8.30$, $2.44 \mathrm{~Hz}$, 3-nitrophenyl $\left.\mathrm{C}_{4}-\mathrm{H}\right), 8.27\left(1 \mathrm{H}, \mathrm{t}, \mathrm{J}=1.95 \mathrm{~Hz}\right.$, 3-nitrophenyl $\left.\mathrm{C}_{2}-\mathrm{H}\right), 10.40(1 \mathrm{H}, \mathrm{s}, \mathrm{CONH})$. Anal. Calcd. for $\mathrm{C}_{23} \mathrm{H}_{19} \mathrm{~N}_{3} \mathrm{O}_{5} \mathrm{~S}$ (449.48): $\mathrm{C}, 61.46 ; \mathrm{H}, 4.26 ; \mathrm{N}$, 9.35. Found: $\mathrm{C}, 61.68 ; \mathrm{H}, 4.16 ; \mathrm{N}, 9.12$.

N-[2-(4-Nitrophenyl)-4-oxo-1,3-thiazolidin-3-yl]-2-hydroxy-2,2-diphenylacetamide (3m)

Yield 40\%; M.p.: 232-235 ${ }^{\circ} \mathrm{C}$; IR (KBr) ( $\left.\bar{\nu}, \mathrm{cm}^{-1}\right): 3107,3360(\mathrm{O}-\mathrm{H} / \mathrm{N}-\mathrm{H}), 1676,1719$ (C=O); ${ }^{1} \mathrm{H}-\mathrm{NMR}$ (DMSO- $\left.d_{6}, 500 \mathrm{MHz}\right) \delta(\mathrm{ppm}): 3.75,3.93\left(2 \mathrm{H}, 2 \mathrm{dd}, J=16.11,1.95 \mathrm{~Hz}\right.$, thiazolidine $\left.\mathrm{C}_{5}-\mathrm{H}\right), 5.93(1 \mathrm{H}, \mathrm{s}$, thiazolidine $\left.\mathrm{C}_{2}-\mathrm{H}\right), 6.76(1 \mathrm{H}, \mathrm{s}, \mathrm{C}-\mathrm{OH}), 7.11(2 \mathrm{H}, \mathrm{dd}, \mathrm{J}=7.81,0.98 \mathrm{~Hz}, \mathrm{Ar}-\mathrm{H}), 7.14-7.19(3 \mathrm{H}, \mathrm{m}, \mathrm{Ar}-\mathrm{H}), 7.22-7.27(5 \mathrm{H}, \mathrm{m}, \mathrm{Ar}-$ $\mathrm{H})$, $7.68\left(2 \mathrm{H}, \mathrm{dd}, J=8.79,1.95 \mathrm{~Hz}\right.$, 4-nitrophenyl $\left.\mathrm{C}_{2,6}-\mathrm{H}\right), 8.08\left(2 \mathrm{H}, \mathrm{dd}, J=8.79,1.95 \mathrm{~Hz}\right.$, 4-nitrophenyl $\left.\mathrm{C}_{3,5}-\mathrm{H}\right)$, 
10.43 (1H, s, CONH). Anal. Calcd. for $\mathrm{C}_{23} \mathrm{H}_{19} \mathrm{~N}_{3} \mathrm{O}_{5} \mathrm{~S}$ (449.48): C, 61.46; $\mathrm{H}, 4.26 ; \mathrm{N}, 9.35$. Found: $\mathrm{C}, 61.76$; $\mathrm{H}, 3.97$; N, 9.71.

\section{N-[2-(2,4-Dinitrophenyl)-4-oxo-1,3-thiazolidin-3-yl]-2-hydroxy-2,2-diphenylacetamide (3n)}

Yield 47\%; M.p.: 206-207 ${ }^{\circ} \mathrm{C}$; IR (KBr) $\left(\bar{\nu}, \mathrm{cm}^{-1}\right): 3213,3372(\mathrm{O}-\mathrm{H} / \mathrm{N}-\mathrm{H}), 1676,1709$ (C=O); ${ }^{1} \mathrm{H}-\mathrm{NMR}$ (DMSO- $\left.d_{6}, 500 \mathrm{MHz}\right) \delta(\mathrm{ppm}): 3.76,3.93\left(2 \mathrm{H}, 2 \mathrm{dd}, J=16.11,1.95 \mathrm{~Hz}\right.$, thiazolidine $\left.\mathrm{C}_{5}-\mathrm{H}\right), 5.94(1 \mathrm{H}$, brs, thiazolidine $\left.\mathrm{C}_{2}-\mathrm{H}\right), 6.76(1 \mathrm{H}, \mathrm{s}, \mathrm{C}-\mathrm{OH}), 7.10-7.27(10 \mathrm{H}, \mathrm{m}, \mathrm{Ar}-\mathrm{H}), 7.68\left(1 \mathrm{H}, \mathrm{d}, J=8,79 \mathrm{~Hz}, 2,4\right.$-dinitrophenyl $\mathrm{C}_{6^{-}}$ $\mathrm{H})$, 8.06-8.09 $\left(2 \mathrm{H}, \mathrm{m}, 2,4\right.$-dinitrophenyl $\left.\mathrm{C}_{2,5}-\mathrm{H}\right), 10.41(1 \mathrm{H}, \mathrm{s}, \mathrm{CONH})$. Anal. Calcd. for $\mathrm{C}_{23} \mathrm{H}_{18} \mathrm{~N}_{3} \mathrm{O}_{7} \mathrm{~S}$ (494.47): C, 55.87; H, 3.67; N, 11.33. Found: C, 55.48; H, 3.55; N, 11.18 .

N-[2-(4-Chloro-3-nitrophenyl)-4-oxo-1,3-thiazolidin-3-yl]-2-hydroxy-2,2-diphenylacetamide (3o)

Yield 45\%; M.p.: 187-188 ${ }^{\circ} \mathrm{C}$; IR (KBr) $\left(\bar{\nu}, \mathrm{cm}^{-1}\right): 3365$ (O-H/N-H), 1678, 1724 (C=O); ${ }^{1} \mathrm{H}-\mathrm{NMR}$ (DMSO$\left.d_{6}, 500 \mathrm{MHz}\right) \delta(\mathrm{ppm}): 3.64,3.85\left(2 \mathrm{H}, 2 \mathrm{~d}, J=15.84 \mathrm{~Hz}\right.$, thiazolidine $\left.\mathrm{C}_{5}-\mathrm{H}\right), 5.79(1 \mathrm{H}, \mathrm{d}, J=5.79 \mathrm{~Hz}$, thiazolidine $\left.\mathrm{C}_{2}-\mathrm{H}\right), 6.67(1 \mathrm{H}, \mathrm{s}, \mathrm{C}-\mathrm{OH}), 6.96-7.17(10 \mathrm{H}, \mathrm{m}, \mathrm{Ar}-\mathrm{H}), 7.54,7.62(2 \mathrm{H}, 2 \mathrm{~d}, J=8.36 \mathrm{~Hz}, \mathrm{Ar}-\mathrm{H}), 8.02,8.12(1 \mathrm{H}, 2 \mathrm{~d}$, $J=2.00 \mathrm{~Hz}, \mathrm{Ar}-\mathrm{H}), 10.36(1 \mathrm{H}, \mathrm{s}, \mathrm{CONH})$. Anal. Calcd. for $\mathrm{C}_{23} \mathrm{H}_{18} \mathrm{ClN}_{3} \mathrm{O}_{5} \mathrm{~S}$ (483.92): C, 57.08; H, 3.75; N, 8.68. Found: $\mathrm{C}, 56.85 ; \mathrm{H}, 3.83 ; \mathrm{N}, 8.38$.

N-[2-(4-Dimethylaminophenyl)-4-oxo-1,3-thiazolidin-3-yl]-2-hydroxy-2,2-diphenylacetamide (3p)

Yield 43\%; M.p.: 196-198 ㄷ; IR (KBr) ( $\left.\bar{\nu}, \mathrm{cm}^{-1}\right): 3208$ (O-H/N-H), 1687, 1727 (C=O); ${ }^{1} \mathrm{H}-\mathrm{NMR}$ (DMSO$\left.d_{6}, 500 \mathrm{MHz}\right) \delta(\mathrm{ppm}): 2.93\left(6 \mathrm{H}, \mathrm{s}, 2 \times \mathrm{CH}_{3}\right), 3.66,3.75\left(2 \mathrm{H}, 2 \mathrm{dd}, J=16.11,1.46 \mathrm{~Hz}\right.$, thiazolidine $\left.\mathrm{C}_{5}-\mathrm{H}\right), 5.72(1 \mathrm{H}$, $\mathrm{s}$, thiazolidine $\left.\mathrm{C}_{2}-\mathrm{H}\right), 6.64\left(2 \mathrm{H}, \mathrm{d}, J=8.79 \mathrm{~Hz}\right.$, 4-dimethylaminophenyl $\left.\mathrm{C}_{3,5}-\mathrm{H}\right), 6.67(1 \mathrm{H}, \mathrm{s}, \mathrm{COH}), 7.07(2 \mathrm{H}$, brs, 4-dimethylaminophenyl $\left.\mathrm{C}_{2,6}-\mathrm{H}\right), 7.18(2 \mathrm{H}, \mathrm{t}, \mathrm{J}=7.32 \mathrm{~Hz}, \mathrm{Ar}-\mathrm{H}), 7.21-7.27(8 \mathrm{H}, \mathrm{m}, \mathrm{Ar}-\mathrm{H}), 10.09(1 \mathrm{H}, \mathrm{s}, \mathrm{CONH})$. Anal. Calcd. for $\mathrm{C}_{25} \mathrm{H}_{25} \mathrm{~N}_{3} \mathrm{O}_{3} \mathrm{~S}$ (447.54): C, 67.09; H, 5.63; N, 9.39. Found: $\mathrm{C}, 67.40 ; \mathrm{H}, 5.37 ; \mathrm{N}, 9.65$.

N-[2-(2-Methylphenyl)-5-methyl-4-oxo-1,3-thiazolidin-3-yl]-2-hydroxy-2,2-diphenylacetamide (4a)

Yield 45\%; M.p.: 224-226 ${ }^{\circ} \mathrm{C}$; IR (KBr) ( $\left.\bar{\nu}, \mathrm{cm}^{-1}\right): 3288,3371$ (O-H/N-H), 1675, $1714(\mathrm{C}=\mathrm{O}) ;{ }^{1} \mathrm{H}-\mathrm{NMR}$ (DMSO- $\left.d_{6}, 500 \mathrm{MHz}\right) \delta(\mathrm{ppm}): 1.48\left(3 \mathrm{H}, \mathrm{d}, J=6.83 \mathrm{~Hz}, 5-\mathrm{CH}_{3}\right), 2.14\left(3 \mathrm{H}, \mathrm{s}, \mathrm{C}_{2}-\mathrm{CH}_{3}\right), 3.98,4.03(1 \mathrm{H}, 2 \mathrm{br} \mathrm{s}$, thiazolidine $\left.\mathrm{C}_{5}-\mathrm{H}\right), 6.11\left(1 \mathrm{H}\right.$, s, thiazolidine $\left.\mathrm{C}_{2}-\mathrm{H}\right), 6.72(1 \mathrm{H}, \mathrm{s}, \mathrm{C}-\mathrm{OH}), 7.11(2 \mathrm{H}, \mathrm{d}, \mathrm{J}=6.83 \mathrm{~Hz}, \mathrm{Ar}-\mathrm{H}), 7.20(12 \mathrm{H}$, br s, Ar-H), $10.31(1 \mathrm{H}, \mathrm{s}, \mathrm{CONH})$. Anal. Calcd. for $\mathrm{C}_{25} \mathrm{H}_{24} \mathrm{~N}_{2} \mathrm{O}_{3} \mathrm{~S}$ (432.53): C, 69.42; H, 5.59; N, 6.48. Found: C, 69.22; H, 5.62; N, 6.39 .

\section{N-[2-(3-Methylphenyl)-5-methyl-4-oxo-1,3-thiazolidin-3-yl]-2-hydroxy-2,2-diphenylacetamide (4b)}

Yield 65\%; M.p.: 178-179 ${ }^{\circ} \mathrm{C}$; IR (KBr) $\left(\bar{\nu}, \mathrm{cm}^{-1}\right): 3296,3388(\mathrm{O}-\mathrm{H} / \mathrm{N}-\mathrm{H}), 1682,1714(\mathrm{C}=\mathrm{O}) ;{ }^{1} \mathrm{H}-\mathrm{NMR}$ (DMSO- $\left.d_{6}, 500 \mathrm{MHz}\right) \delta$ (ppm): 1.51-1.53 $\left(3 \mathrm{H}, \mathrm{m}, 5-\mathrm{CH}_{3}\right), 2.27\left(3 \mathrm{H}, \mathrm{s}, \mathrm{C}_{3}-\mathrm{CH}_{3}\right), 3.99,4.09(1 \mathrm{H}, 2 \mathrm{q}, J=6.83 \mathrm{~Hz}$, thiazolidine $\left.\mathrm{C}_{5}-\mathrm{H}\right), 5.79\left(1 \mathrm{H}, \mathrm{s}\right.$, thiazolidine $\left.\mathrm{C}_{2}-\mathrm{H}\right), 6.70(1 \mathrm{H}, \mathrm{s}, \mathrm{C}-\mathrm{OH}), 7.16-7.18(3 \mathrm{H}, \mathrm{m}, \mathrm{Ar}-\mathrm{H}), 7.21-7.25(6 \mathrm{H}$, $\mathrm{m}, \mathrm{Ar}-\mathrm{H}), 7.27(5 \mathrm{H}, \mathrm{d}, \mathrm{J}=5.37 \mathrm{~Hz}, \mathrm{Ar}-\mathrm{H}), 10.24(1 \mathrm{H}, \mathrm{s}, \mathrm{CONH})$. Anal. Calcd. for $\mathrm{C}_{25} \mathrm{H}_{24} \mathrm{~N}_{2} \mathrm{O}_{3} \mathrm{~S}$ (432.53): C, 69.42; $\mathrm{H}, 5.59 ; \mathrm{N}, 6.48$. Found: C, 69.16; H, 5.72; N, 6.44.

\section{N-[2-(4-Methylphenyl)-5-methyl-4-oxo-1,3-thiazolidin-3-yl]-2-hydroxy-2,2-diphenylacetamide (4c)}

Yield 35\%; M.p.: 187-188 C; IR (KBr) ( $\left.\bar{\nu}, \mathrm{cm}^{-1}\right): 3397$ (O-H/N-H), 1682, 1717 (C=O); ${ }^{1} \mathrm{H}-\mathrm{NMR}$ (DMSO$\left.d_{6}, 500 \mathrm{MHz}\right) \delta(\mathrm{ppm}): 1.50\left(3 \mathrm{H}, \mathrm{d}, J=3.42 \mathrm{~Hz}, 5-\mathrm{CH}_{3}\right), 2.31\left(3 \mathrm{H}, \mathrm{d}, J=3.42 \mathrm{~Hz}, \mathrm{C}_{4}-\mathrm{CH}_{3}\right), 3.97,4.07(1 \mathrm{H}, 2 \mathrm{~d}, J=6.83$, $0.93 \mathrm{~Hz}$, thiazolidine $\left.\mathrm{C}_{5}-\mathrm{H}\right), 5.74\left(1 \mathrm{H}\right.$, s, thiazolidine $\left.\mathrm{C}_{2}-\mathrm{H}\right), 6.67(1 \mathrm{H}, \mathrm{s}, \mathrm{C}-\mathrm{OH}), 7.12(2 \mathrm{H}, \mathrm{d}, J=7.81 \mathrm{~Hz}, 4-$ methylphenyl $\left.\mathrm{C}_{3,5}-\mathrm{H}\right), 7.19(2 \mathrm{H}, \mathrm{t}, J=6.83, \mathrm{Ar}-\mathrm{H}), 7.22-7.27(8 \mathrm{H}, \mathrm{m}, \mathrm{Ar}-\mathrm{H}), 7.30(2 \mathrm{H}, \mathrm{d}, J=8.30,3.42 \mathrm{~Hz}, 4-$ methylphenyl $\left.\mathrm{C}_{2,6}-\mathrm{H}\right), 10.23(1 \mathrm{H}, \mathrm{s}, \mathrm{CONH})$. Anal. Calcd. for $\mathrm{C}_{25} \mathrm{H}_{24} \mathrm{~N}_{2} \mathrm{O}_{3} \mathrm{~S}$ (432.53): C, 69.42; $\mathrm{H}, 5.59 ; \mathrm{N}, 6.48$. Found: C, 69.38; H, 5.87; N, 6.28.

N-[2-(2-Hydroxyphenyl)-5-methyl-4-oxo-1,3-thiazolidin-3-yl]-2-hydroxy-2,2-diphenylacetamide (4d)

Yield 58\%; M.p.: 234-235 ㄷ; IR (KBr) ( $\left.\bar{\nu}, \mathrm{cm}^{-1}\right): 3278$ (O-H/N-H), 1673, 1705 (C=O); ${ }^{1} \mathrm{H}-\mathrm{NMR}$ (DMSO$\left.d_{6}, 500 \mathrm{MHz}\right) \delta(\mathrm{ppm}): 1.46\left(3 \mathrm{H}, \mathrm{d}, J=6.83 \mathrm{~Hz}, 5-\mathrm{CH}_{3}\right), 3.92,4.00\left(1 \mathrm{H}, 2 \mathrm{q}, J=6.83 \mathrm{~Hz}\right.$, thiazolidine $\left.\mathrm{C}_{5}-\mathrm{H}\right), 6.18(1 \mathrm{H}$, $\mathrm{s}$, thiazolidine $\left.\mathrm{C}_{2}-\mathrm{H}\right), 6.73(1 \mathrm{H}, \mathrm{s}, \mathrm{C}-\mathrm{OH}), 6.78\left(1 \mathrm{H}, \mathrm{d}, J=7.81 \mathrm{~Hz}\right.$, 2-hydroxyphenyl $\left.\mathrm{C}_{3}-\mathrm{H}\right), 6.81(2 \mathrm{H}, \mathrm{dd}, J=8.30$, $0.98 \mathrm{~Hz}$, 2-hydroxyphenyl $\left.\mathrm{C}_{5,6}-\mathrm{H}\right), 7.13\left(1 \mathrm{H}, \mathrm{td}, J=7.32,1.46 \mathrm{~Hz}\right.$, 2-hydroxyphenyl $\left.\mathrm{C}_{4}-\mathrm{H}\right), 7.21-7.25(10 \mathrm{H}, \mathrm{m}, \mathrm{Ar}-$ $\mathrm{H}), 9.83(1 \mathrm{H}, \mathrm{s}, 2-\mathrm{OH}), 10.23(1 \mathrm{H}, \mathrm{s}, \mathrm{CONH})$. Anal. Calcd. for $\mathrm{C}_{24} \mathrm{H}_{22} \mathrm{~N}_{2} \mathrm{O}_{4} \mathrm{~S}$ (434.50): C, 66.34; H, 5.10; N, 6.45 . Found: C, 65.99; H, 5.01; N, 6.54 . 
N-[2-(4-Hydroxyphenyl)-5-methyl-4-oxo-1,3-thiazolidin-3-yl]-2-hydroxy-2,2-diphenylacetamide (4e)

Yield 54\%; M.p.: 235-236 ${ }^{\circ} \mathrm{C}$; IR (KBr) ( $\left.\bar{\nu}, \mathrm{cm}^{-1}\right): 3372$ (O-H/N-H), 1661, 1710 (C=O); ${ }^{1} \mathrm{H}-\mathrm{NMR}$ (DMSO$\left.d_{6}, 500 \mathrm{MHz}\right) \delta(\mathrm{ppm}): 1.50\left(3 \mathrm{H}, \mathrm{d}, J=6.34 \mathrm{~Hz}, 5-\mathrm{CH}_{3}\right), 3.94,4.03\left(1 \mathrm{H}, 2 \mathrm{q}, J=6.83 \mathrm{~Hz}\right.$, thiazolidine $\left.\mathrm{C}_{5}-\mathrm{H}\right), 5.70$, $5.73\left(1 \mathrm{H}, 2 \mathrm{~s}\right.$, thiazolidine $\left.\mathrm{C}_{2}-\mathrm{H}\right), 6.70-6.73(3 \mathrm{H}, \mathrm{m}, \mathrm{COH}$ and $\mathrm{Ar}-\mathrm{H}), 7.10(2 \mathrm{H}, \mathrm{brs}, \mathrm{Ar}-\mathrm{H}), 7.21-7.24(5 \mathrm{H}, \mathrm{m}, \mathrm{Ar}-$ $\mathrm{H})$, 7.27-7.28 (5H, m, Ar-H), $10.12(1 \mathrm{H}, \mathrm{s}, \mathrm{CONH})$. Anal. Calcd. for $\mathrm{C}_{24} \mathrm{H}_{22} \mathrm{~N}_{2} \mathrm{O}_{4} \mathrm{~S}(434.50): \mathrm{C}, 66.34 ; \mathrm{H}, 5.10 ; \mathrm{N}$, 6.45. Found: $\mathrm{C}, 66.55 ; \mathrm{H}, 5.32 ; \mathrm{N}, 6.32$.

N-[2-(3-Ethoxy-4-hydroxyphenyl)-5-methyl-4-oxo-1,3-thiazolidin-3-yl]-2-hydroxy-2,2-diphenylacetamide (4f)

Yield 65\%; M.p.: 202-203 ${ }^{\circ} \mathrm{C}$; IR (KBr) ( $\left.\bar{\nu}, \mathrm{cm}^{-1}\right): 3381$ (O-H/N-H), 1672, 1713 (C=O); ${ }^{1} \mathrm{H}-\mathrm{NMR}$ (DMSO$\left.d_{6}, 500 \mathrm{MHz}\right) \delta(\mathrm{ppm}): 1.28\left(3 \mathrm{H}, \mathrm{t}, J=7.32 \mathrm{~Hz}, 3-\mathrm{OCH}_{2} \mathrm{CH}_{3}\right), 1.48\left(3 \mathrm{H}, \mathrm{d}, J=6.83 \mathrm{~Hz}, 5-\mathrm{CH}_{3}\right), 3.85-3.99(3 \mathrm{H}, \mathrm{m}$, thiazolidine $\mathrm{C}_{5}-\mathrm{H}$ and 3-OCH $\left.\mathrm{CH}_{3}\right), 5.75\left(1 \mathrm{H}, \mathrm{s}\right.$, thiazolidine $\left.\mathrm{C}_{2}-\mathrm{H}\right), 6.95(1 \mathrm{H}, \mathrm{s}, \mathrm{C}-\mathrm{OH}), 6.67-6.73(2 \mathrm{H}, \mathrm{m}, 3-$ ethoxy-4-hydroxyphenyl $\left.\mathrm{C}_{5,6}-\mathrm{H}\right), 6.95\left(1 \mathrm{H}, \mathrm{s}\right.$, 3-ethoxy-4-hydroxyphenyl $\left.\mathrm{C}_{2}-\mathrm{H}\right), 7.18-7.27(10 \mathrm{H}, \mathrm{m}, \mathrm{Ar}-\mathrm{H}), 8.49$ (1H, s, 4-OH), 10.20 (1H, s, CONH). Anal. Calcd. for $\mathrm{C}_{26} \mathrm{H}_{26} \mathrm{~N}_{2} \mathrm{O}_{5} \mathrm{~S}$ (478.56): C, 65.25; H, 5.48; N, 5.85. Found: C, $65.16 ; \mathrm{H}, 5.60 ; \mathrm{N}, 5.49$.

N-[2-(4-Hydroxy-3-methoxy-5-nitrophenyl)-5-methyl-4-oxo-1,3-thiazolidin-3-yl]-2-hydroxy-2,2-diphenylacetamide $(4 g)$

Yield 70\%; M.p.: 238-239 ${ }^{\circ} \mathrm{C}$; IR (KBr) ( $\left.\overline{\boldsymbol{V}}, \mathrm{cm}^{-1}\right): 3346(\mathrm{O}-\mathrm{H} / \mathrm{N}-\mathrm{H}), 1673,1706$ (C=O); ${ }^{1} \mathrm{H}-\mathrm{NMR}$ (DMSO$\left.d_{6}, 500 \mathrm{MHz}\right) \delta(\mathrm{ppm}): 1.39\left(3 \mathrm{H}, \mathrm{t}, J=6.73 \mathrm{~Hz}, 5-\mathrm{CH}_{3}\right), 3.55\left(3 \mathrm{H}, \mathrm{d}, J=5.70 \mathrm{~Hz}, \mathrm{OCH}_{3}\right), 3.85,3.94(1 \mathrm{H}, 2 \mathrm{q}, J=7.00 \mathrm{~Hz}$, thiazolidine $\left.\mathrm{C}_{5}-\mathrm{H}\right), 5.63\left(1 \mathrm{H}\right.$, s, thiazolidine $\left.\mathrm{C}_{2}-\mathrm{H}\right), 6.76(1 \mathrm{H}, \mathrm{brs}, \mathrm{C}-\mathrm{OH}), 7.10-7.14(10 \mathrm{H}, \mathrm{m}, \mathrm{Ar}-\mathrm{H}), 7.30-7.32$ $(2 \mathrm{H}, \mathrm{m}, \mathrm{Ar}-\mathrm{H}), 10.16(1 \mathrm{H}, \mathrm{s}, \mathrm{CONH})$. Anal. Calcd. for $\mathrm{C}_{25} \mathrm{H}_{23} \mathrm{~N}_{3} \mathrm{O}_{7} \mathrm{~S}$ (509.53): C, 58.93; H, 4.55; N, 8.25. Found: C, 58.65; H, 4.72; N, 8.44.

N-[2-(4-Methoxyphenyl)-5-methyl-4-oxo-1,3-thiazolidin-3-yl]-2-hydroxy-2,2-diphenylacetamide (4h)

Yield 68\%; M.p.: 175-176 ${ }^{\circ} \mathrm{C}$; IR (KBr) $\left(\bar{\nu}, \mathrm{cm}^{-1}\right): 3300,3401(\mathrm{O}-\mathrm{H} / \mathrm{N}-\mathrm{H}), 1687,1715(\mathrm{C}=\mathrm{O}) ;{ }^{1} \mathrm{H}-\mathrm{NMR}$ (DMSO- $\left.d_{6}, 500 \mathrm{MHz}\right) \delta(\mathrm{ppm}): 1.51\left(3 \mathrm{H}, \mathrm{d}, J=7.08 \mathrm{~Hz}, 5-\mathrm{CH}_{3}\right), 3.78\left(3 \mathrm{H}, \mathrm{d}, J=2.45 \mathrm{~Hz}, \mathrm{C}_{4}-\mathrm{OCH}_{3}\right), 3.97,4.06(1 \mathrm{H}$, $2 \mathrm{q}, \mathrm{J}=6.83 \mathrm{~Hz}$, thiazolidine $\left.\mathrm{C}_{5}-\mathrm{H}\right), 5.77\left(1 \mathrm{H}, \mathrm{s}\right.$, thiazolidine $\left.\mathrm{C}_{2}-\mathrm{H}\right), 6.67(1 \mathrm{H}$, brs, $\mathrm{C}-\mathrm{OH}), 6.86-6.89(2 \mathrm{H}, \mathrm{m}, \mathrm{Ar}-\mathrm{H})$, 7.11-7.12 (2H, m, Ar-H), 7.18-7.29 (8H, m, Ar-H), 7.33-7.36 (6H, m, Ar-H), 10.18 (1H, s, CONH). Anal. Calcd. for $\mathrm{C}_{25} \mathrm{H}_{24} \mathrm{~N}_{2} \mathrm{O}_{4} \mathrm{~S}$ (448.54): C, 66.95; H, 5.39; N, 6.25. Found: $\mathrm{C}, 66.60 ; \mathrm{H}, 5.65 ; \mathrm{N}, 6.18$.

N-[2-(3,4-Dimethoxyphenyl)-5-methyl-4-oxo-1,3-thiazolidin-3-yl]-2-hydroxy-2,2-diphenylacetamide (4i)

Yield 31\%; M.p.: 138-139 C; IR (KBr) ( $\left.\bar{\nu}, \mathrm{cm}^{-1}\right): 3337$ (O-H/N-H), 1674, 1707 (C=O); ${ }^{1} \mathrm{H}-\mathrm{NMR}$ (DMSO$\left.d_{6}, 500 \mathrm{MHz}\right) \delta(\mathrm{ppm}): 1.51\left(3 \mathrm{H}, \mathrm{d}, J=4.39 \mathrm{~Hz}, 5-\mathrm{CH}_{3}\right), 3.67\left(3 \mathrm{H}, \mathrm{s}, \mathrm{OCH}_{3}\right), 3.76\left(3 \mathrm{H}, \mathrm{s}, \mathrm{OCH}_{3}\right), 3.97,4.05(1 \mathrm{H}$, 2qd, J=6.83, $1.46 \mathrm{~Hz}$, thiazolidine $\left.\mathrm{C}_{5}-\mathrm{H}\right), 5.75\left(1 \mathrm{H}, \mathrm{s}\right.$, thiazolidine $\left.\mathrm{C}_{2}-\mathrm{H}\right), 6.70(1 \mathrm{H}, \mathrm{brs}, \mathrm{C}-\mathrm{OH}), 7.05(1 \mathrm{H}, \mathrm{s}, 3,4-$ dimethoxyphenyl $\left.\mathrm{C}_{2}-\mathrm{H}\right), 6.84\left(1 \mathrm{H}, \mathrm{dd}, J=8.30,3.42 \mathrm{~Hz}, 3,4\right.$-dimethoxyphenyl $\left.\mathrm{C}_{6}-\mathrm{H}\right), 6.88(1 \mathrm{H}, \mathrm{td}, J=8.30,1.95$ $\mathrm{Hz}$, 3,4-dimethoxyphenyl $\left.\mathrm{C}_{5}-\mathrm{H}\right)$, 7.09-7.26 (10H, m, Ar-H), 7.33-7.36 (6H, m, Ar-H), $10.24(1 \mathrm{H}, \mathrm{s}, \mathrm{CONH})$. Anal. Calcd. for $\mathrm{C}_{26} \mathrm{H}_{26} \mathrm{~N}_{2} \mathrm{O}_{5} \mathrm{~S}$ (478.56): C, 65.25; $\mathrm{H}, 5.48 ; \mathrm{N}, 5.85$. Found: $\mathrm{C}, 65.47 ; \mathrm{H}, 5.75 ; \mathrm{N}, 5.71$.

N-[2-(2,5-Dimethoxyphenyl)-5-methyl-4-oxo-1,3-thiazolidin-3-yl]-2-hydroxy-2,2-diphenylacetamide (4j)

Yield 54\%; M.p.: 172-173 ${ }^{\circ} \mathrm{C}$; IR (KBr) ( $\left.\bar{\nu}, \mathrm{cm}^{-1}\right): 3342$ (O-H/N-H), 1675, 1710 (C=O); ${ }^{1} \mathrm{H}-\mathrm{NMR}$ (DMSO$\left.d_{6}, 500 \mathrm{MHz}\right) \delta(\mathrm{ppm}): 1.47\left(3 \mathrm{H}, \mathrm{d}, J=6.83 \mathrm{~Hz}, 5-\mathrm{CH}_{3}\right), 3.64\left(3 \mathrm{H}, \mathrm{s}, \mathrm{OCH}_{3}\right), 3.66\left(3 \mathrm{H}, \mathrm{s}, \mathrm{OCH}_{3}\right), 3.93,4.03(1 \mathrm{H}$, 2qd, J=6.83, $1.95 \mathrm{~Hz}$, thiazolidine $\left.\mathrm{C}_{5}-\mathrm{H}\right), 6.14\left(1 \mathrm{H}, \mathrm{s}\right.$, thiazolidine $\left.\mathrm{C}_{2}-\mathrm{H}\right), 6.76(1 \mathrm{H}, \mathrm{s}, \mathrm{C}-\mathrm{OH}), 6.84(1 \mathrm{H}, \mathrm{dd}, J=2.93$, $1.46 \mathrm{~Hz}, 2$,4-dimethoxyphenyl $\left.\mathrm{C}_{3}-\mathrm{H}\right), 6.92\left(1 \mathrm{H}, \mathrm{dd}, J=9.27,1.46 \mathrm{~Hz}, 2,4\right.$-dimethoxyphenyl $\left.\mathrm{C}_{5}-\mathrm{H}\right), 7.20(1 \mathrm{H}, \mathrm{d}$, $J=82.93 \mathrm{~Hz}, 2$,4-dimethoxyphenyl $\left.\mathrm{C}_{6}-\mathrm{H}\right), 7.24-7.27(10 \mathrm{H}, \mathrm{m}, \mathrm{Ar}-\mathrm{H}), 10.29(1 \mathrm{H}, \mathrm{s}, \mathrm{CONH})$. Anal. Calcd. for $\mathrm{C}_{26} \mathrm{H}_{26} \mathrm{~N}_{2} \mathrm{O}_{5} \mathrm{~S}$ (478.56): C, 65.25; H, 5.48; N, 5.85. Found: C, 64.95; H, 5.32; N, 5.78.

$\mathrm{N}$-[2-(4-Methoxycarbonylphenyl)-5-methyl-4-oxo-1,3-thiazolidin-3-yl]-2-hydroxy-2,2-diphenylacetamide (4k)

Yield 77\%; M.p.: 167-168 ${ }^{\circ} \mathrm{C}$; IR (KBr) $\left(\bar{\nu}, \mathrm{cm}^{-1}\right): 3322(\mathrm{O}-\mathrm{H} / \mathrm{N}-\mathrm{H}), 1669,1704$ (C=O); ${ }^{1} \mathrm{H}-\mathrm{NMR}$ (DMSO$\left.d_{6}, 500 \mathrm{MHz}\right) \delta(\mathrm{ppm}): 1.52\left(3 \mathrm{H}, \mathrm{d}, J=7.32 \mathrm{~Hz}, 5-\mathrm{CH}_{3}\right), 3.88\left(3 \mathrm{H}, \mathrm{s}, 4-\mathrm{COOCH}_{3}\right), 4.03,4.15(1 \mathrm{H}, 2 \mathrm{qd}, J=6.83,1.46$ $\mathrm{Hz}$, thiazolidine $\left.\mathrm{C}_{5}-\mathrm{H}\right), 5.86\left(1 \mathrm{H}, \mathrm{s}\right.$, thiazolidine $\left.\mathrm{C}_{2}-\mathrm{H}\right), 6.71(1 \mathrm{H}, \mathrm{s}, \mathrm{C}-\mathrm{OH})$, 7.07-7.11 $(2 \mathrm{H}, \mathrm{m}, \mathrm{Ar}-\mathrm{H})$, 7.14-7.18 $(2 \mathrm{H}, \mathrm{m}, \mathrm{Ar}-\mathrm{H}), \quad 7.19-7.22(3 \mathrm{H}, \mathrm{m}, \mathrm{Ar}-\mathrm{H}), 7.24-7.27(3 \mathrm{H}, \mathrm{m}, \mathrm{Ar}-\mathrm{H}), 7.56(2 \mathrm{H}, \mathrm{dd}, J=8.30,1.95 \mathrm{~Hz}, 4-$ methoxycarbonylphenyl $\left.\mathrm{C}_{2,6}-\mathrm{H}\right), 7.86\left(2 \mathrm{H}, \mathrm{d}, J=8.30 \mathrm{~Hz}\right.$, 4-methoxycarbonylphenyl $\left.\mathrm{C}_{3,5}-\mathrm{H}\right), 10.34(1 \mathrm{H}, \mathrm{s}$, $\mathrm{CONH}$ ). Anal. Calcd. for $\mathrm{C}_{26} \mathrm{H}_{24} \mathrm{~N}_{2} \mathrm{O}_{5} \mathrm{~S}$ (476.55): C, 65.53; H, 5.08; N, 5.88. Found: C, 65.60; H, 4.96; N, 5.88. 


\section{N-[2-(2-Nitrophenyl)-5-methyl-4-oxo-1,3-thiazolidin-3-yl]-2-hydroxy-2,2-diphenylacetamide (4l)}

Yield 50\%; M.p.: 164-165 ${ }^{\circ} \mathrm{C}$; IR (KBr) $\left(\bar{\nu}, \mathrm{cm}^{-1}\right): 3263,3369$ (O-H/N-H), 1681, 1717 (C=O) ${ }^{1} \mathrm{H}-\mathrm{NMR}$ (DMSO- $\left.d_{6}, 500 \mathrm{MHz}\right) \delta(\mathrm{ppm}): 1.50\left(3 \mathrm{H}, \mathrm{d}, J=6.83 \mathrm{~Hz}, 5-\mathrm{CH}_{3}\right), 4.02,4.15(1 \mathrm{H}, 2 \mathrm{dd}, J=6.83,1.46 \mathrm{~Hz}$, thiazolidine $\left.\mathrm{C}_{5}-\mathrm{H}\right), 6.16\left(1 \mathrm{H}, \mathrm{s}\right.$, thiazolidine $\left.\mathrm{C}_{2}-\mathrm{H}\right), 6.80(1 \mathrm{H}, \mathrm{s}, \mathrm{C}-\mathrm{OH}), 7.14-7.25(10 \mathrm{H}, \mathrm{m}, \mathrm{Ar}-\mathrm{H}), 7.60(1 \mathrm{H}, \mathrm{dd}, J=6.83,1.46$ $\mathrm{Hz}$, 2-nitrophenyl $\left.\mathrm{C}_{4}-\mathrm{H}\right), 7.75\left(1 \mathrm{H}, \mathrm{dd}, \mathrm{J}=7.81,0.98 \mathrm{~Hz}\right.$, 2-nitrophenyl $\left.\mathrm{C}_{6}-\mathrm{H}\right), 8.01-8.04$ (2H, m, 2-nitrophenyl $\left.\mathrm{C}_{3,5}-\mathrm{H}\right), 10.33(1 \mathrm{H}, \mathrm{s}, \mathrm{CONH})$. Anal. Calcd. for $\mathrm{C}_{24} \mathrm{H}_{21} \mathrm{~N}_{3} \mathrm{O}_{5} \mathrm{~S}$ (463.50): C, 62.19; H, 4.57; N, 9.07. Found: C, 62.57; $\mathrm{H}, 4.37 ; \mathrm{N}, 8.82$.

\section{N-[2-(3-Nitrophenyl)-5-methyl-4-oxo-1,3-thiazolidin-3-yl]-2-hydroxy-2,2-diphenylacetamide (4m)}

Yield 53\%; M.p.: 198-199 ${ }^{\circ} \mathrm{C}$; IR (KBr) $\left(\bar{\nu}, \mathrm{cm}^{-1}\right): 3329,3385(\mathrm{O}-\mathrm{H} / \mathrm{N}-\mathrm{H}), 1676,1724$ (C=O); ${ }^{1} \mathrm{H}-\mathrm{NMR}$ (DMSO- $\left.d_{6}, 500 \mathrm{MHz}\right) \delta(\mathrm{ppm}): 1.55\left(3 \mathrm{H}, \mathrm{d}, J=7.32 \mathrm{~Hz}, 5-\mathrm{CH}_{3}\right), 4.06,4.21(1 \mathrm{H}, 2 \mathrm{qd}, J=7.32,1.46 \mathrm{~Hz}$, thiazolidine $\left.\mathrm{C}_{5}-\mathrm{H}\right), 5.93\left(1 \mathrm{H}, \mathrm{s}\right.$, thiazolidine $\left.\mathrm{C}_{2}-\mathrm{H}\right), 6.73(1 \mathrm{H}, \mathrm{s}, \mathrm{C}-\mathrm{OH}), 7.06-7.10(2 \mathrm{H}, \mathrm{m}, \mathrm{Ar}-\mathrm{H}), 7.14-7.25(8 \mathrm{H}, \mathrm{m}, \mathrm{Ar}-\mathrm{H}), 7.57$ $\left(1 \mathrm{H}, \mathrm{t}, \mathrm{J}=8.30 \mathrm{~Hz}, 3\right.$-nitrophenyl $\left.\mathrm{C}_{5}-\mathrm{H}\right), 7.86\left(1 \mathrm{H}, \mathrm{d}, \mathrm{J}=7.81 \mathrm{~Hz}, 3\right.$-nitrophenyl $\left.\mathrm{C}_{6}-\mathrm{H}\right), 8.15(1 \mathrm{H}, \mathrm{d}, \mathrm{J}=7.80 \mathrm{~Hz}, 3-$ nitrophenyl $\left.\mathrm{C}_{4}-\mathrm{H}\right), 8.28\left(1 \mathrm{H}, \mathrm{q}, J=1.95 \mathrm{~Hz}, 3\right.$-nitrophenyl $\left.\mathrm{C}_{2}-\mathrm{H}\right), 10.41(1 \mathrm{H}, \mathrm{s}, \mathrm{CONH})$. Anal. Calcd. for $\mathrm{C}_{24} \mathrm{H}_{21} \mathrm{~N}_{3} \mathrm{O}_{5} \mathrm{~S}$ (463.50): C, 62.19; H, 4.57; N, 9.07. Found: C, 62.35; H, 4.84; N, 9.10.

\section{N-[2-(4-Nitrophenyl)-5-methyl-4-oxo-1,3-thiazolidin-3-yl]-2-hydroxy-2,2-diphenylacetamide (4n)}

Yield 70\%; M.p.: 121-122 ${ }^{\circ} \mathrm{C}$; IR (KBr) $\left(\bar{\nu}, \mathrm{cm}^{-1}\right): 3274,3461(\mathrm{O}-\mathrm{H} / \mathrm{N}-\mathrm{H}), 1673,1714(\mathrm{C}=\mathrm{O})$; ${ }^{1} \mathrm{H}-\mathrm{NMR}$ (DMSO-d $6,500 \mathrm{MHz}) \delta(\mathrm{ppm}): 1.52,1.54\left(3 \mathrm{H}, 2 \mathrm{~d}, \mathrm{~J}=7.32 \mathrm{~Hz}, 5-\mathrm{CH}_{3}\right), 4.07,4.19(1 \mathrm{H}, 2 \mathrm{q}, \mathrm{J}=6.83 \mathrm{~Hz}$, thiazolidine $\left.\mathrm{C}_{5}-\mathrm{H}\right), 5.92-5.93\left(1 \mathrm{H}, \mathrm{m}\right.$, thiazolidine $\left.\mathrm{C}_{2}-\mathrm{H}\right), 6.73(1 \mathrm{H}, \mathrm{s}, \mathrm{COH}), 7.10-7.21(5 \mathrm{H}, \mathrm{m}, \mathrm{Ar}-\mathrm{H}), 7.23-7.28(5 \mathrm{H}, \mathrm{m}, \mathrm{Ar}-$ H), $7.69\left(2 \mathrm{H}, \mathrm{d}, J=8.30 \mathrm{~Hz}\right.$, 4-nitrophenyl $\left.\mathrm{C}_{2,6}-\mathrm{H}\right), 8.08(2 \mathrm{H}, \mathrm{d}, J=8.05 \mathrm{~Hz}$, 4-nitrophenyl C $3,5-\mathrm{H}), 10.40,10.41(1 \mathrm{H}$, s, CONH); ${ }^{13} \mathrm{C}-\mathrm{NMR}(\mathrm{APT})\left(\mathrm{DMSO}-d_{6} / 125 \mathrm{MHz}\right) \delta(\mathrm{ppm}): 20.40\left(5-\mathrm{CH}_{3}\right), 38.41\left(\mathrm{C}_{5}\right), 60.44\left(\mathrm{C}_{2}\right), 81.16(\mathrm{C}-\mathrm{OH})$, 123.95, 127.95, 128.14, 128.23, 130.17, 130.50 (Ar. CH), 144.07, 144.10, 145.33 (Ar. C), 148.40 (Ar. C-NO (A) $_{171.69}$ (amide $\mathrm{C}=\mathrm{O}$ ), 172.23 (lactam $\mathrm{C}=\mathrm{O}$ ); LC/MS: $m / z 462(\mathrm{M}-\mathrm{H})^{-}$. Anal. Calcd. for $\mathrm{C}_{24} \mathrm{H}_{21} \mathrm{~N}_{3} \mathrm{O}_{5} \mathrm{~S}$ (463.50): C, 62.19; $\mathrm{H}, 4.57 ; \mathrm{N}, 9.07$. Found: C, 62.53; H, 4.46; N, 8.88.

\section{N-[2-(4-Chloro-3-nitrophenyl)-5-methyl-4-oxo-1,3-thiazolidin-3-yl]-2-hydroxy-2,2-diphenylacetamide (4o)}

Yield 46\%; M.p.: 180-181 ${ }^{\circ} \mathrm{C}$; IR (KBr) $\left(\bar{\nu}, \mathrm{cm}^{-1}\right): 3387$ (O-H/N-H), 1674, 1721 (C=O); ${ }^{1} \mathrm{H}-\mathrm{NMR}$ (DMSO$\left.d_{6}, 500 \mathrm{MHz}\right) \delta(\mathrm{ppm}): 1.52\left(3 \mathrm{H}, \mathrm{d}, J=6.83 \mathrm{~Hz}, 5-\mathrm{CH}_{3}\right), 4.05,4.20\left(1 \mathrm{H}, 2 \mathrm{q}, \mathrm{J}=6.83 \mathrm{~Hz}\right.$, thiazolidine $\left.\mathrm{C}_{5}-\mathrm{H}\right), 5.90(1 \mathrm{H}$, s, thiazolidine $\left.\mathrm{C}_{2}-\mathrm{H}\right), 6.79(1 \mathrm{H}$, brs, C-OH), 7.12-7.15 (2H, m, Ar-H), 7.19-7.26 (8H, m, Ar-H), 7.64 (1H, d, J=8.30 $\mathrm{Hz}$, 4-chloro-3-nitrophenyl $\left.\mathrm{C}_{5}-\mathrm{H}\right), 7.72\left(1 \mathrm{H}, \mathrm{dd}, J=8.30,1.95 \mathrm{~Hz}, 4\right.$-chloro-3-nitrophenyl $\left.\mathrm{C}_{6}-\mathrm{H}\right), 8.10(1 \mathrm{H}, \mathrm{s}, 4-$ chloro-3-nitrophenyl $\left.\mathrm{C}_{2}-\mathrm{H}\right), 10.46(1 \mathrm{H}, \mathrm{s}, \mathrm{CONH})$. Anal. Calcd. for $\mathrm{C}_{24} \mathrm{H}_{20} \mathrm{ClN}_{3} \mathrm{O}_{5} \mathrm{~S}$ ( 497.95): C, 57.89; H, 4.05; N, 8.44. Found: C, 57.55; H, 3.98; N, 7.30.

\section{N-[2-(4-Dimethylaminophenyl)-5-methyl-4-oxo-1,3-thiazolidin-3-yl]-2-hydroxy-2,2-diphenylacetamide (4p)}

Yield 33\%; M.p.: 184-185 ${ }^{\circ} \mathrm{C}$; IR (KBr) ( $\left.\overline{\boldsymbol{V}}, \mathrm{cm}^{-1}\right): 3264$ (O-H/N-H), 1674, 1709 (C=O); ${ }^{1} \mathrm{H}-\mathrm{NMR}$ (DMSO$\left.d_{6}, 500 \mathrm{MHz}\right) \delta(\mathrm{ppm}): 1.51\left(3 \mathrm{H}, \mathrm{d}, J=6.83 \mathrm{~Hz}, 5-\mathrm{CH}_{3}\right), 2.93\left(6 \mathrm{H}, \mathrm{d}, J=1.46 \mathrm{~Hz}, \mathrm{~N}\left(\mathrm{CH}_{3}\right)_{2}\right), 3.94,4.02(1 \mathrm{H}, 2 \mathrm{q}, J=6.83$ $\mathrm{Hz}$, thiazolidine $\left.\mathrm{C}_{5}-\mathrm{H}\right), 5.69,5.73\left(1 \mathrm{H}, 2 \mathrm{~s}\right.$, thiazolidine $\left.\mathrm{C}_{2}-\mathrm{H}\right), 6.65(1 \mathrm{H}, \mathrm{d}, \mathrm{J}=7.32 \mathrm{~Hz}, \mathrm{C}-\mathrm{OH}), 7.11(2 \mathrm{H}, \mathrm{d}, \mathrm{J}=5.37$ $\mathrm{Hz}, \mathrm{Ar}-\mathrm{H}), 7.19-7.23$ (6H, m, Ar-H), 7.25-7.28 (6H, m, Ar-H), 10.10 (1H, s, CONH); ${ }^{13} \mathrm{C}-\mathrm{NMR}$ (APT) (DMSO$\left.d_{6} / 125 \mathrm{MHz}\right) \delta(\mathrm{ppm}): 20.89\left(5-\mathrm{CH}_{3}\right), 39.31\left(\mathrm{C}_{5}\right), 40.28,40.44\left(\mathrm{~N}\left(\mathrm{CH}_{3}\right)_{2}\right), 61.37\left(\mathrm{C}_{2}\right), 81.24(\mathrm{C}-\mathrm{OH}), 112.39,112.44$, 127.94, 127.96, 128.08, 128.12, 128.16, 128.38, 128.41, 130.28 (Ar. CH), 144.14, 144.17, 144.28 (ar. CH), 171.84 (amide $\mathrm{C}=\mathrm{O}$ ), 172.04 (lactam $\mathrm{C}=\mathrm{O}$ ). LC/MS: $m / z 460(\mathrm{M}-\mathrm{H})^{-}$. Anal. Calcd. for $\mathrm{C}_{26} \mathrm{H}_{27} \mathrm{~N}_{3} \mathrm{O}_{3} \mathrm{~S}$ (461.57): C, 67.65; H, 5.90; N, 9.10. Found: C, 67.96; H, 5.97; N, 8.98.

\subsection{In vitro evaluation of anticancer activity}

To provide growth on the cancer screening panel for the cell lines used in the study, RPMI medium with $5 \%$ fetal bovine serum and $2 \mathrm{mM}$ L-glutamine was used. Inoculation of cells into 96 well microtiter plates in $100 \mu \mathrm{L}$ was done according to the doubling time of each single cell line. The plating cell density ranged between 5,000 - 40,000 cells per well. Following this, a $24 \mathrm{~h}$ condition for the incubation process of microtiter plates was set at $37{ }^{\circ} \mathrm{C}, 95 \%$ air, $5 \% \mathrm{CO}_{2}$, and $100 \%$ relative humidity and the experimental drugs were eventually added at time Tz. To determine the cell population for individual cell lines at time Tz, two plates of individual cell lines were bounded in situ using trichloroacetic acid. To provide two-fold of the wanted maximum final concentration that contains a complete medium of gentamicin $(50 \mu \mathrm{g} / \mathrm{ml})$ at time $\mathrm{Tz}$, a frozen portion of the concentrate was defrosted and diluted. In addition to the control, a further series of dilutions were conducted to obtain a concentration of $1 / 2 \log$, fourfold, or 10 fold giving a sum of five drug 
concentrations. To each suitable microtiter well that accommodates the medium $(100 \mu \mathrm{l})$, a $100 \mu \mathrm{l}$ portion of each of the various drug concentrations were added to obtain the necessary final drug concentrations. The incubation was continued for another two days under the same conditions as mentioned above. The assay for the adherent cells was discontinued after adding a cold TCA. Subsequently, $50 \mu 1$ of cold $50 \%(\mathrm{w} / \mathrm{v}$ ) trichloroacetic acid was gently added to bind the cells in situ and at $4^{\circ} \mathrm{C}$, the incubation continued for another $1 \mathrm{~h}$. The plates were thoroughly washed with $\mathrm{H}_{2} \mathrm{O}$ and left to dry after discarding the supernatant. At room temperature, plates were incubated for 10 minutes after the addition of $0.4 \%(\mathrm{w} / \mathrm{v}) 100 \mu \mathrm{l}$ solution of Sulforhodamine B (SRB) in 1\% acetic acid to each well. By using 1\% acetic acid, the excess dye was removed at the end of the staining process. This was done by washing five times, after which the plates were dried. Dissolving bound stain in $10 \mathrm{mM}$ trizma base, an automated plate reader was used to measure the absorbance at a wavelength of $515 \mathrm{~nm}$. The aforesaid methodology was applied for suspension cells, however, the termination of the assay was done by soft addition of $50 \mu \mathrm{l}$ of $80 \%$ TCA This helped in fixing the settled cells at the bottom of the wells. The calculation of the growth percentage was done by using seven absorbance records for each drug concentration. The percentage of growth inhibition was calculated using the equations (Eq. 1, Eq. 2) below:

$$
\begin{array}{ll}
\frac{T i-T z}{C-T z} \times 100, \text { when } T i \geq T z & \text { Eq. } 1 \\
\frac{T i-T z}{T z} \times 100, \text { when } T i<T z & \text { Eq. } 2
\end{array}
$$

Tz=Time zero, $C=$ Control growth,$T i=$ Test growth in the presence of drugs at the five concentration levels

For each experimental agent, the three dose-response parameters were calculated. $50 \%$ growth inhibition $\left(\mathrm{GI}_{50}\right)$, the drug concentration during the drug incubation measured by SRB staining and resulted in a $50 \%$ decrease in the net protein increase in control cells, was determined with the formula $\frac{T i-T z}{C-T z} \times 100=$ 50. Total growth inhibition from drug concentration was determined using $\mathrm{Ti}=\mathrm{Tz}$. The concentration of the drug that results in a $50 \%$ reduction $\left(\mathrm{LC}_{50}\right)$ in the measured protein, was compared at the end of the drug treatment. The initial concentration (beginning) and that of the end of the treatment showed a net loss of cells following treatment. This was calculated using the formula $\frac{T i-T z}{T z} \times 100=-50$. For each of these parameters, values were calculated, if the level of the activity was reached. However, the values are expressed as greater or less than the maximum or minimum tested concentration, if the effect was not reached or exceeded.

Acknowledgments: We are grateful to the Division of Cancer Research, National Cancer Institute, Bethesda, Maryland, for the anticancer activity screening. This study was funded by Istanbul University with project number 1918.

Author contributions: Concept - Ö.G.-A.; Design - Ö.G.-A.; Supervision - Ö.G.-A; Resources - Ö.G.-A; Materials Ö.G.-A.; Data Collection and/or Processing - Ö.G.-A., K.D.-Y.; Analysis and/or Interpretation - Ö.G.-A., K.D.-Y.; Literature Search - Ö.G.-A., K.D.-Y..; Writing - Ö.G.-A., K.D.-Y.; Critical Reviews - Ö.G.-A., K.D.-Y.

Conflict of interest statement: The authors declared no conflict of interest.

Appendix A. Supplementary Material

Supplementary material related to this article can be accessed at https://dx.doi.org/10.29228/jrp.21 .

\section{REFERENCES}

[1] Ferlay J, Colombet M, Soerjomataram I, Mathers C, Parkin DM, Piñeros M, Znaor A, Bray F. Estimating the Global Cancer Incidence and Mortality in 2018: GLOBOCAN Sources and Methods. Int J Cancer. 2019; 144(8): $1941-1953$. [CrossRef]

[2] Goodarzi E, Khazaei Z, Moayed L, Adineh HA, Sohrabivafa M, Darvishi I, Dehghani SL. Epidemiology and Population Attributable Fraction of Melanoma to Ultraviolet Radiation in Asia: An Ecological Study. World Cancer Res J. 2018; 5(3): e1114. 
[3] Bray F, Ferlay J, Soerjomataram I, Siegel RL, Torre LA, Jemal A. Global Cancer Statistics 2018: GLOBOCAN Estimates of Incidence and Mortality Worldwide for 36 Cancers in 185 Countries. CA Cancer J Clin. 2018; 68(6): 394-424. [CrossRef]

[4] Miller KD, Siegel RL, Lin CC, Mariotto AB, Kramer JL, Rowland JH, Stein KD, Alteri R, Jemal A. Cancer Treatment and Survivorship Statistics. 2016. CA Cancer J Clin. 2016; 66(4): 271-289. [CrossRef]

[5] Roy PS, Saikia BJ. Cancer and Cure: A Critical Analysis. Indian J Cancer. 2016; 53(3): 441-442.

[6] Pejović A, Minić A, Bugarinović J, Pešić M, Damljanović I, Stevanović D, Mihailović V, Katanić J, Bogdanović GA. Synthesis, Characterization and Antimicrobial Activity of Novel 3-Ferrocenyl-2-pyrazolyl-1,3-thiazolidin-4-ones. Polyhedron. 2018; 155: 382-389. [CrossRef]

[7] Verma A, Saraf SK. 4-Thiazolidinone - A Biologically Active Scaffold. Eur J Med Chem. 2008; 43(5): 897-905. [CrossRef]

[8] Kunzler A, Neuenfeldt PD, Das Neves AM, Pereira CMP, Marques GH, Nascente PS, Fernandes MHV, Hübner SO, Cunico W. Synthesis, Antifungal and Cytotoxic Activities of 2-Aryl-3-((piperidin-1-yl)ethyl)thiazolidinones. Eur J Med Chem. 2013; 64: 74-80. [CrossRef]

[9] Küçükgüzel ŞG, Oruç EE, Rollas S, Şahin F, Özbek A. Synthesis, Characterisation and Biological Activity of Novel 4Thiazolidinones, 1,3,4-Oxadiazoles and Some Related Compounds. Eur J Med Chem. 2002; 37(3): 197-206. [CrossRef]

[10] D'Ascenzio M, Bizzarri B, De Monte C, Carradori S, Bolasco A, Secci D, Rivanera D, Faulhaber N, Bordón C, JonesBrando L. Design, Synthesis and Biological Characterization of Thiazolidin-4-one Derivatives as Promising Inhibitors of Toxoplasma gondii. Eur J Med Chem. 2014; 86: 17-30. [CrossRef]

[11] Secci D, Carradori S, Bizzarri B, Chimenti P, De Monte C, Mollica A, Rivanera D, Zicari A, Mari E, Zengin G, Aktumsek A. Novel 1,3-Thiazolidin-4-one Derivatives as Promising Anti-Candida Agents Endowed with Antioxidant and Chelating Properties. Eur J Med Chem. 2016; 117: 144-156. [CrossRef]

[12] Tripathi AC, Gupta SJ, Fatima GN, Sonar PK, Verma A, Saraf SK. 4-Thiazolidinones: The Advances Continue. Eur J Med Chem. 2014; 72: 52-77. [CrossRef]

[13] Jain AK, Vaidya A, Ravichandran V, Kashaw SK, Agrawal RK. Recent Developments and Biological Activities of Thiazolidinone Derivatives: A Review. Bioorganic Med Chem. 2012; 20(11): 3378-3395. [CrossRef]

[14] Güzel Ö, Salman A. Synthesis and Biological Evaluation of New 4-Thiazolidinone Derivatives. J Enzyme Inhib Med Chem 2009, 24(4): 1015-1023. 24:1015-1023. [CrossRef]

[15] Güzel Ö, Ilhan E, Salman A. Synthesis and Antimycobacterial Activity of New 2-Hydroxy-N-(3-oxo-1-thia- 4azaspiro[4.4]non-4-yl)/(3-oxo-1-thia-4-azaspiro[4.5]dec-4-yl)-2, 2-diphenylacetamide Derivatives. Monatsh Chem. 2006; 137(6): 795-801. [CrossRef]

[16] Ulusoy Güzeldemirci N, Pehlivan E, Naesens L. Synthesis and Antiviral Activity Evaluation of New 4Thiazolidinones Bearing an Imidazo[2,1-b]thiazole Moiety. Marmara Pharm J. 2018; 22(2): 237-248. [CrossRef]

[17] Kaynak FB, Öztürk D, Özbey S, Çapan G. New N'-Alkylidene/cycloalkylidene Derivatives of 5-Methyl-3-phenyl1H-indole-2-carbohydrazide: Synthesis, Crystal Structure, and Quantum Mechanical Calculations. J Mol Struct. 2005; 740(1-3): 213-221. [CrossRef]

[18] Taylor PJ. The Infra-red Spectroscopy of Some 2-Substituted Thiazolid-4-ones, a New Class of Enamino-ketone-II. Infra-red Assignments and Chemical Implications. Spectrochim Acta Part A Mol Spectrosc. 1970; 26(1): 165-194. [CrossRef]

[19] Gupta A, Singh R, Sonar PK, Saraf SK. Novel 4-Thiazolidinone Derivatives as Anti-infective Agents: synthesis, Characterization, and Antimicrobial Evaluation. Biochem Res Int. 2016; 2016: 1-8. [CrossRef]

[20] Karali N, Ilhan E, Gürsoy A, Kiraz M. New yclohexylidenehydrazide and 4-Aza-1-thiaspiro[4.5]decan-3-one Derivatives of 3-Phenyl-4 (3H)-quinazolinones. Farmaco. 1998; 53(5): 346-349. [CrossRef]

[21] Ulusoy N. Synthesis and Antituberculosis Activity of Cycloalkylidenehydrazide and 4-Aza-1-thiaspiro[4.5]decan-3one Derivatives of Imidazo[2,1-b]thiazole. Arzneimittel-Forschung/Drug Res. 2002; 52(07): 565-571. [CrossRef]

[22] Peters R, Hellenbrand J, Mengerink Y, Van Der Wal S. On-line Determination of Carboxylic Acids, Aldehydes and Ketones by High-Performance Liquid Chromatography-Diode Array Detection-Atmospheric Pressure Chemical Ionisation Mass Spectrometry After Derivatization with 2-Nitrophenylhydrazine. J Chromatogr A. 2004; 1031(1-2): 35-50. [CrossRef]

[23] De Lima WT, De Lima JG, Góes AJS. Mass Spectrometry of Some N-Tryptophyl-4-Thiazolidinone and N-Tryptophyl5-benzylidene-4-thiazolidinone Derivatives. Spectrosc Lett. 2002; 35(1): 137-144. [CrossRef] 
[24] Alley MC, Scudiero DA, Monks A, Hursey M, Czerwinski MJ, Fine DL, Abbott BJ, Mayo JG, Shoemaker R, Boyd MR. Feasibility of Drug Screening with Panels of Human Tumor Cell Lines Using a Microculture Tetrazolium Assay. Cancer Res. 1988; 48(3): 584-588.

[25] Grever MR, Schepartz SA, Chabner BA. The National Cancer Institute: Cancer Drug Discovery and Development Program. Semin Oncol. 1992; 19(6): 622.

[26] Boyd MR, Paull KD. Some Practical Considerations and Applications of the National Cancer Institute in vitro Anticancer Drug Discovery Screen. Drug Dev Res. 1995; 34(2): 91-109. [CrossRef]

[27] Rollas S, Büyüktimkin S, Büyüktimkin N, Ulgen M, Yemni E. Evaluation of Some Arylhydrazones of N2Arylidenebenzylic Acid Hydrazide as Antimicrobial Agents. Pharmazie. 1988; 43(7): 511.

[28] Abu Safieh K, Al-Titi AM, Zahra J, Ayoub M. Oxidative Cyclization of Arylidene Carboxyhydrazides : Synthesis of Substituted Hydroxydiphenylmenthyl-3,3,4-oxadiazoles. Jordan J Chem. 2007; 2(3): 211-218.

[29] Issa YM, Issa RM, Abdel-Latif SA, Abdel-Salam HA. Structural Studies of Cu(II) Chelates with Some Arylidene Derivatives of Benzilic Hydrazide. Monatsh Chem. 1998; 129(1): 19-29. [CrossRef]

[30] Issa RM, Abdel-Latif SA, Abdel-Salam HA. Synthesis and Characterization of New Cu(II) Complexes Derived from Benzilic and Mandelic Hydrazones. Synth React Inorg Met Chem. 2001; 31(1): 95-105. [CrossRef]

This is an open access article which is publicly available on our journal's website under Institutional Repository at http://dspace.marmara.edu.tr. 